\title{
Historical Spatial and Temporal Climate Trends in Southern Ontario, Canada $\mathscr{O}$
}

\author{
Hussein WaZnEH AND M. Altaf ARAin \\ School of Geography and Earth Sciences, and McMaster Centre for Climate Change, McMaster University, \\ Hamilton, Ontario, Canada \\ PAulin COUliBAly \\ Department of Civil Engineering, McMaster University, Hamilton, Ontario, Canada
}

(Manuscript received 26 August 2016, in final form 10 July 2017)

\begin{abstract}
Spatial and temporal trends in historical temperature and precipitation extreme events were evaluated for southern Ontario, Canada. A number of climate indices were computed using observed and regional and global climate datasets for the area of study over the 1951-2013 period. A decrease in the frequency of cold temperature extremes and an increase in the frequency of warm temperature extremes was observed in the region. Overall, the numbers of extremely cold days decreased and hot nights increased. Nighttime warming was greater than daytime warming. The annual total precipitation and the frequency of extreme precipitation also increased. Spatially, for the precipitation indices, no significant trends were observed for annual total precipitation and extremely wet days in the southwest and the central part of Ontario. For temperature indices, cool days and warm night have significant trends in more than $90 \%$ of the study area. In general, the spatial variability of precipitation indices is much higher than that of temperature indices. In terms of comparisons between observed and simulated data, results showed large differences for both temperature and precipitation indices. For this region, the regional climate model was able to reproduce historical observed trends in climate indices very well as compared with global climate models. The statistical biascorrection method generally improved the ability of the global climate models to accurately simulate observed trends in climate indices.
\end{abstract}

\section{Introduction}

Climate change is described by nonstationarity in both mean and extreme values of climate variables such as temperature and precipitation. Many studies have shown large variations in the magnitude and shape of extreme values of climate variables in recent years (e.g., Alexander et al. 2006; Frich et al. 2002; Moberg and Jones 2005). Based on the latest report of the Intergovernmental Panel on Climate Change (IPCC 2013), and for the $90 \%$ uncertainty level, the global average surface temperature has increased by $0.85^{\circ} \mathrm{C}$ (with a range of $0.65^{\circ}-1.06^{\circ} \mathrm{C}$ ) during the $1880-2012$ period. This temperature increase was accompanied by nonuniform

Supplemental information related to this paper is available at the Journals Online website: https://doi.org/10.1175/JAMC-D-160290.s1.

Corresponding author: M. Altaf Arain, arainm@mcmaster.ca variations in temporal and spatial patterns of precipitation in various regions across the world.

In Canada, several studies provided a comprehensive analysis of temperature and precipitation trends in the twentieth century (e.g., Rapaić et al. 2015; Vincent et al. 2015; Zhang et al. 2000; Zhang et al. 2011). They showed a $1^{\circ} \mathrm{C}$ increase in the mean annual temperature and $5 \%-35 \%$ increases in annual total precipitation over the last half of the twentieth century. At the local level, Mohsin and Gough (2010) analyzed the trend in the annual mean and minimum temperatures in the greater Toronto area for the 1970-2000 period. They showed that the temperature in urban areas is increasing by more than $0.1^{\circ} \mathrm{C}$ decade $^{-1}$ relative to adjacent rural areas, which means that urbanization is contributing to the observed warming trend as well. Adamowski et al. (2010) analyzed annual short-duration extreme rainfall for 15 stations in the Canadian province of Ontario and found increasing trends but with a nonuniform rate of change for all short durations. Razavi et al. (2016) studied past 
and future trends in temperature and precipitation across the Hamilton region of Ontario using a range of downscaled climate models. They showed an increasing trend for the mean and maximum temperature and annual total precipitation over various time periods in the twenty-first century. These changes in climatic conditions will have severe implications for the environment, ecosystems, economy, and the health of people in Canada as a result of its northern location (Warren and Lemmen 2014).

Analyzing changes and trends in extreme climate and weather events is challenging because of the complex nature of climatic processes and the temporal and spatial dynamics of their associated variables. To characterize extreme climate and weather events in an easyto-understand and usable form for urban planners, farmers, policy-makers and general users, a set of 27 indices describing the extremes of climate variables has been defined by the Expert Team on Climate Change Detection and Indices (ETCCDI) (e.g., Gent et al. 2011; Peterson and Manton 2008). These indices can be classified into three different types. The first type measures the monthly and the annual maxima (or minima), such as the annual total precipitation amounts. These types of indices are widely used in engineering applications to infer design values for buildings and structures. Another type of indices involves the number of days exceeding a fixed threshold during a given year, such as the number of frost days per year, which is the number of days in a year when the minimum temperature drops below $0^{\circ} \mathrm{C}$. These types of indices may not be applicable in all geographic regions and are not suitable for global comparison (Gent et al. 2011). The third type of indices involves the calculation of the number of days in a year exceeding a percentile threshold, for example the cool nights, which are defined as the number of days with daily minimum temperature below the long-term 10th percentile in the 1965-90 base period. These types of extreme climate and weather indices are suitable for temporal and spatial comparisons.

Although a number of studies have examined historical temperature and precipitation trends in Canada using a number of indices (e.g., Bonsal et al. 2001; Vincent and Mekis 2006; Vincent et al. 2012; Vincent et al. 2015; Zhang et al. 2000; Zhang et al. 2011), they focused on the national and regional scales. In particular, Vincent and Mekis (2006) found fewer cold nights, cold days, and frost days, and conversely found more warm nights, warm days, and summer days across Canada. They also found more days with precipitation and a decrease in the maximum number of consecutive dry days. At the regional scale, Bonsal et al. (2001) found an increasing trend in both lower and higher percentiles of daily maximum and minimum temperatures from 1900 to
1998 for the southern part of Canada. To our knowledge, there are no studies in the literature that focus on examining and quantifying the trends in historical climate and extreme weather events using a suite of observed and simulated climate indices at the local or small regional scales, such as southern Ontario, which houses one-third of Canada's population and is an important hub of economic activity.

The primary objective of this study is to analyze the historical temporal and spatial variability of key indices of climate extremes at the local scale across southern Ontario. To this end, we have computed four temperature and four precipitation indices using observed weather data [from Environment and Climate Change Canada, formerly known as Environment Canada, (ECCC)] and the Canadian Gridded dataset (CanGrid; McKenney et al. 2011) and examined their trends to provide a better understanding of the past and future changes in the intensity, frequency, and duration of extreme weather events in the region. We also evaluated the capacity of the Canadian Regional Climate Model, version 4 (CanRCM; Caya and Laprise 1999; Laprise et al. 1998), and three general circulation models (GCMs) of the Coupled Model Intercomparison Project, phase 5 (IPCC-AR5; Maurer et al. 2007; Brekke et al. 2013), to simulate the historical temperature and precipitation indices and their trends across the study area. The results of this study can be seen as an important step forward in characterizing and quantifying the effects of climate change and extreme weather events at the local scale, in an area that is prone to extreme weather events and that has profound significance for Canada, both socially and economically.

\section{Methods and materials}

\section{a. Study region and datasets}

\section{1) STUDY REGION}

The study was conducted in southern Ontario (Fig. 1), encompassing an area of about $100000 \mathrm{~km}^{2}$ and located between $42^{\circ} 18^{\prime} \mathrm{N}, 83^{\circ} 01^{\prime} \mathrm{W}$ and $45^{\circ} 31^{\prime} \mathrm{N}, 74^{\circ} 06^{\prime} \mathrm{W}$. This region is the most densely populated area in Canada and is home to about 11 million people, which represents almost one-third of the country's population and $75 \%$ of the provincial population. The climate in the study area is cool continental, which is influenced by local and regional effects due its proximity to the Great Lakes (Paixao et al. 2011).

\section{2) OBSERVED DATASETS}

The observed daily precipitation and the maximum and minimum surface air temperatures for this study 


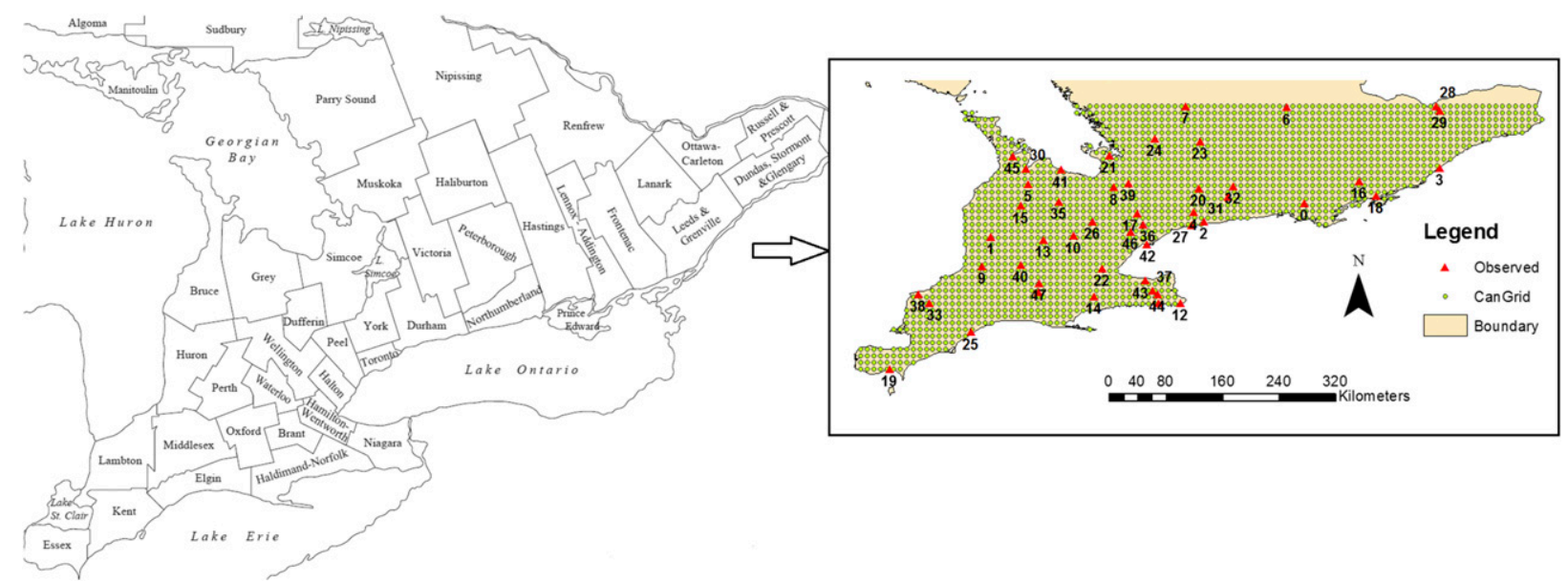

FIG. 1. Study location in Ontario, Canada. Red triangles represent 48 ECCC weather stations (see Table 1). Green circles represent 1699 grid points (approximately $10 \mathrm{~km} \times 10 \mathrm{~km}$ ) of CanGrid data in the study area.

were obtained from data archives of 48 meteorological stations, operated by the ECCC across southern Ontario. The location and details of these stations are shown in Fig. 1 and Table 1. We also utilized gridded historical weather station data (CanGrid) produced by McKenney et al. (2011) using the Natural Resources Canada and ECCC data at $0.0833^{\circ}$ spatial resolution (approximately $10 \mathrm{~km} \times 10 \mathrm{~km}$ ). These data were generated using the ANUSPLIN software package (see http:// fennerschool.anu.edu.au/research/products/anusplin-vrsn-44). This method has been used in many studies in the past (e.g., Cannon et al. 2015; Hopkinson et al. 2011). Data from 1699 CanGrid grids located in southern Ontario were used in our study (Fig. 1).

\section{3) REgiOnAL AND GLOBAL CLIMATE MODEL DATASETS}

Regional and global climate models are an essential tool for analyzing the present and future climates. However, there is large uncertainty associated with the use of these models due to their course spatial resolution or inadequate incorporation of certain physical processes and associated parameterizations. The choice of the GCM used in the climate trend analysis poses the biggest challenge since it is the main source of uncertainty in the climate change impact studies (Minville et al. 2008). Therefore, utilization of ensemble or multimodel historical and future climate projections is recommended and has the advantage of capturing the full range of possible climate change scenarios and accounting for possible biases associated with individual models (Tebaldi and Knutti 2007).

Therefore, in this study, we used simulated regridded climate data from three GCMs: the Canadian Earth System Model (CanESM2), the Community Climate System
Model (CCSM4), and the Community Earth System Model, version 1 (biogeochemistry) [CESM1(BGC)]. These are the most recent Canadian and U.S. GCMs, and were part of the IPCC's Fifth Assessment Report and the Coupled Model Intercomparison Project, phase 5 (CMIP5) (e.g., Brekke et al. 2013; Taylor et al. 2012). These data are archived by the U.S. Department of the Interior's Bureau of Reclamation at $100-\mathrm{km}$ spatial resolution. To explain the full range of the variability, we used the averages across all model runs for the CanESM2 and CCSM4 models (the only models that provided data for multiple simulations) in our study. In addition, simulated data from the Canadian Regional Climate Model (CanRCM), version 4, were also used. CanRCM has 40-km spatial resolution and is driven by the CanESM2, and shares the same physical schemes as this global climate model (Caya and Laprise 1999). More model data details are given in Table 2.

\section{b. Climate indices}

Eight indices of climate extremes-four for precipitation and four for temperatures-were selected for this study (Table 3). Temperature extremes include warm night (TN90), cool day (TX10), annual minimum of daily minimum temperature ( $\mathrm{TNn}$ ), and annual maximum of daily maximum temperature (TXx). Precipitation indices include the annual total precipitation (PRCPTOT), extremely wet day (R99p), consecutive dry day (CDD), and consecutive wet day (CWD). Threshold indices (i.e., R99p, TN90, and TX100) were also computed using the reference period 1965-90, if at least $70 \%$ of the data were available, which is the normal period widely used in literature (Gent et al. 2011; Zhang et al. 2011). These selected temperatures 
TABLE 1. Details of the 48 weather stations located in the studied area. Here and below, ID indicates the station identifier.

\begin{tabular}{|c|c|c|c|c|c|c|c|}
\hline ID & Station name & Start year & End year & Lat $\left(^{\circ}\right)$ & Lon $\left(^{\circ}\right)$ & Elev (m) & Length $(\mathrm{m})$ \\
\hline 0 & Belleville & 1955 & 2015 & 44.1505 & -77.3947 & 76.2 & 60 \\
\hline 1 & Blyth & 1960 & 2010 & 43.7183 & -81.3836 & 350.5 & 50 \\
\hline 2 & Bowmanville: Mostert Greenhouses & 1967 & 2002 & 43.9166 & -78.6667 & 99.1 & 35 \\
\hline 3 & Brockville PCC & 1966 & 2015 & 44.6000 & -75.6667 & 96 & 49 \\
\hline 4 & Burketon Mclaughlin & 1969 & 2002 & 44.0333 & -78.8000 & 312.4 & 33 \\
\hline 5 & Chatsworth & 1953 & 2013 & 44.3950 & -80.9056 & 305 & 60 \\
\hline 6 & Combermere & 1956 & 2009 & 45.3666 & -77.6167 & 286.5 & 53 \\
\hline 7 & Dwight & 1973 & 2005 & 45.3833 & -78.9000 & 404 & 32 \\
\hline 8 & Essa: Hydro One & 1958 & 2001 & 44.3500 & -79.8167 & 216.4 & 43 \\
\hline 9 & Exeter & 1961 & 2008 & 43.3500 & -81.5000 & 262.1 & 47 \\
\hline 10 & Fergus: Shand Dam & 1950 & 2015 & 43.7347 & -80.3303 & 417.6 & 65 \\
\hline 11 & Foldens & 1964 & 2015 & 43.0183 & -80.7808 & 328 & 51 \\
\hline 12 & Fort Erie & 1967 & 2015 & 42.8833 & -78.9667 & 179.8 & 48 \\
\hline 13 & Glen Allan & 1956 & 2013 & 43.6839 & -80.7103 & 400 & 57 \\
\hline 14 & Hagersville & 1950 & 2004 & 42.9666 & -80.0667 & 221 & 54 \\
\hline 15 & Hanover & 1972 & 2008 & 44.1164 & -81.0058 & 270 & 36 \\
\hline 16 & Hartington IHD & 1968 & 2015 & 44.4280 & -76.6903 & 160 & 47 \\
\hline 17 & King Smoke Tree & 1975 & 2003 & 44.0166 & -79.5167 & 352 & 28 \\
\hline 18 & Kingston Pumping Station & 1961 & 2007 & 44.2439 & -76.4806 & 76.5 & 46 \\
\hline 19 & Kingsville MOE & 1961 & 2015 & 42.0430 & -82.6739 & 200 & 54 \\
\hline 20 & Lindsay Frost & 1975 & 2010 & 44.3383 & -78.7403 & 262.1 & 35 \\
\hline 21 & Midland Water Pollution Control Plant & 1960 & 2015 & 44.7577 & -79.8753 & 180 & 55 \\
\hline 22 & Millgrove & 1955 & 2006 & 43.3166 & -79.9667 & 255.1 & 51 \\
\hline 23 & Minden & 1957 & 2011 & 44.9333 & -78.7167 & 274.3 & 54 \\
\hline 24 & Muskoka Airport & 1940 & 2005 & 44.9666 & -79.3000 & 281.9 & 65 \\
\hline 25 & New Glasgow & 1958 & 2015 & 42.5144 & -81.6361 & 198.1 & 57 \\
\hline 26 & Orangeville MOE & 1961 & 2015 & 43.9183 & -80.0864 & 411.5 & 54 \\
\hline 27 & Oshawa Water Pollution Control Plant (WPCP) & 1969 & 2015 & 43.8666 & -78.8333 & 83.8 & 46 \\
\hline 28 & Ottawa CDA & 1950 & 2015 & 45.3833 & -75.7167 & 79.2 & 65 \\
\hline 29 & Ottawa Macdonald-Cartier International Airport & 1950 & 2011 & 45.3225 & -75.6692 & 114 & 61 \\
\hline 30 & Owen Sound MOE & 1965 & 2007 & 44.5833 & -80.9333 & 178.9 & 42 \\
\hline 31 & Peterborough A & 1969 & 2007 & 44.2333 & -78.3667 & 191.4 & 38 \\
\hline 32 & Peterborough: Trent University & 1968 & 2012 & 44.3666 & -78.3000 & 198.1 & 44 \\
\hline 33 & Petrolia Town & 1960 & 2005 & 42.8833 & -82.1667 & 201.2 & 45 \\
\hline 34 & Port Colborne & 1965 & 2015 & 42.8833 & -79.2500 & 175.3 & 50 \\
\hline 35 & Proton Station & 1970 & 2002 & 44.1666 & -80.5167 & 480.1 & 32 \\
\hline 36 & Richmond Hill & 1960 & 2014 & 43.8772 & -79.4478 & 240 & 54 \\
\hline 37 & Ridgeville & 1950 & 2008 & 43.0416 & -79.3250 & 236.2 & 58 \\
\hline 38 & Sarnia Chris Hadfield Airport & 1968 & 2007 & 42.9922 & -82.3047 & 180.6 & 39 \\
\hline 39 & Shanty Bay & 1973 & 2015 & 44.3994 & -79.6328 & 250 & 42 \\
\hline 40 & Stratford Waste Water treatment Plant (WWTP) & 1960 & 2015 & 43.3688 & -81.0047 & 345 & 55 \\
\hline 41 & Thornbury Slama & 1968 & 2005 & 44.5736 & -80.4853 & 213.4 & 37 \\
\hline 42 & Toronto Island A & 1957 & 2006 & 43.6286 & -79.3950 & 76.5 & 49 \\
\hline 43 & Vineland Rittenhouse & 1965 & 2001 & 43.1666 & -79.4167 & 94.5 & 36 \\
\hline 44 & Welland & 1955 & 2013 & 42.9925 & -79.2611 & 175.3 & 58 \\
\hline 45 & Wiarton Airport & 1950 & 2014 & 44.7458 & -81.1072 & 222.2 & 64 \\
\hline 46 & Woodbridge & 1950 & 2005 & 43.7833 & -79.6000 & 164 & 55 \\
\hline 47 & Woodstock & 1950 & 2015 & 43.1361 & -80.7706 & 281.9 & 65 \\
\hline
\end{tabular}

and precipitation indices are adequate for representing both the magnitude and the frequency of extreme temperature and precipitation events over a given period.

\section{c. Analysis procedure}

Our data analysis procedure is composed of three main steps as summarized in Fig. 2. In the first step, we used the observed ECCC and CanGrid data to compute the selected climate indices, as described in the following section, and their related trends. Climate indices and trends computed for the 48 weather stations for the 1961-2013 period (considered to be the "truth") were compared with those obtained using CanGrid data. This comparison helps to show the correlation between the CanGrid and ECCC datasets (generated using observed data as well) in terms of climate index values and 
TABLE 2. GCMs used in the study.

\begin{tabular}{lll}
\hline \hline Modeling center (or group) & Institute ID & Model name \\
\hline $\begin{array}{c}\text { Canadian Centre for Climate } \\
\text { Modeling and Analysis }\end{array}$ & CCCMA & CanESM2 \\
$\begin{array}{c}\text { National Center for } \\
\text { Atmospheric Research }\end{array}$ & NCAR & CCSM4 \\
$\begin{array}{c}\text { Community Earth System } \\
\text { Model contributors }\end{array}$ & NSF-DOE-NCAR & CESM1(BGC) \\
\hline
\end{tabular}

variabilities, which is important for the third step of the procedure we adopted for this analysis. To explore the spatial variability of climate indices in the study area, indices were computed for all 1699 CanGrid grids for the 1951-2013 period, and then their trends were interpolated using an inverse distance weighting (IDW) method, which is described in section $2 \mathrm{f}$. We used the 1971-2013 period, rather than the 1961-2013 time frame used in the comparison of ECCC and CanGrid data, because of the availability of the CanGrid data. In the second step, indices using global and regional datasets were computed. To this end, global and regional model data were extracted for each CanGrid grid location and downscaled using the bias-correction method described in section 2e. CanESM2 and CCSM4 provided data for five and two model simulations, respectively. Therefore, for these two models, the averages across these runs were used to compute climate indices. In the third step, we compared the results obtained using CanGrid (supposed as observations) and climate model data using the performance criteria described in section $2 \mathrm{~g}$. These criteria evaluate the ability of models to simulate the observed indices and the consistency of trends.

\section{d. Significance of trends}

The linear annual trends in historical temperature and precipitation indices were evaluated using the nonparametric test developed by Mann and Kendall (MK; Kendall 1948; Mann 1945). The MK test is usually preferred over other statistical tests because of its robustness and power; this is especially the case for slow phenomena data trends, which is the case for climate indices (Chaouche et al. 2010). Having a vector of time series $x_{1}, \ldots, x_{n}$ an MK test evaluates the rank of each value in the vector with respect to all of the other observation ranks. As a nonparametric, an MK test does not require any assumption about the distribution of the time series (Kadioğlu 1997). This test requires statistically independent observations, which is the case for annual climate indices. The null hypothesis ( $\mathrm{H} 0)$ of no significant trend in the data cannot be rejected if the $p$ value of the test exceeds the significance level (normally taken to be $5 \%$ or $10 \%$ ), while a $p$ value less than the significance level indicates the presence of a statistically significant trend in the data.

\section{e. Bias correction of modeled data}

CanRCM and GCM model simulations are performed at coarse spatial resolution and hence they are not appropriate for local climate change impact studies, in particular for hydrological studies (Dibike and Coulibaly 2007). These models provide poor estimations of the observed climate trends, in terms of both their mean values and their standard deviations. To avoid uncertainty, these simulations must be bias corrected before their use in the local climate impact studies (Sharma et al. 2011). We used a method developed by Ines and Hansen (2006) to bias correct both the temperature and precipitation data. For precipitation, the bias correction was a two-step procedure, which was applied first to correct the precipitation frequency and then to correct the intensity distribution for each month of the year. A gamma distribution was used for both observed and modeled precipitation intensities.

The temperature bias-correction procedure is similar to that for precipitation but without any frequency corrections. A normal distribution was used instead of the gamma distribution for the temperature bias correction. Similarly, a daily climate model temperature distribution was mapped onto the observed distribution for each month of the year. CanGrid data (McKenney et al. 2011) were used as the observed data for the bias correction.

TABLE 3. Precipitation and temperature indices used in the study.

\begin{tabular}{|c|c|c|c|}
\hline ID & Indicator name & Indicator definition & Unit \\
\hline PRCPTOT & Annual total precipitation & Annual total precipitation from days $\geq 1 \mathrm{~mm}$ & $\mathrm{~mm} \mathrm{yr}^{-1}$ \\
\hline R99p & Extremely wet days & Annual total precipitation from days $>99$ th percentile & $\mathrm{mm} \mathrm{yr}^{-1}$ \\
\hline CWD & Consecutive wet days & Max No. of consecutive days when precipitation $\geq 1 \mathrm{~mm}$ & days $\mathrm{yr}^{-1}$ \\
\hline $\mathrm{CDD}$ & Consecutive dry days & Max No. of consecutive days when precipitation $<1 \mathrm{~mm}$ & days $\mathrm{yr}^{-1}$ \\
\hline TX10p & Cool days & No. of day where max temperature $<10$ th percentile & days $\mathrm{yr}^{-1}$ \\
\hline TN90p & Warm nights & No. of day where min temperature $>90$ th percentile & days $\mathrm{yr}^{-1}$ \\
\hline $\mathrm{TNn}$ & Min Tmin & Annual min value of daily min temperature & ${ }^{\circ} \mathrm{C} \mathrm{yr}^{-1}$ \\
\hline TXx & Max Tmax & Annual max value of daily max temperature & 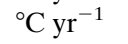 \\
\hline
\end{tabular}




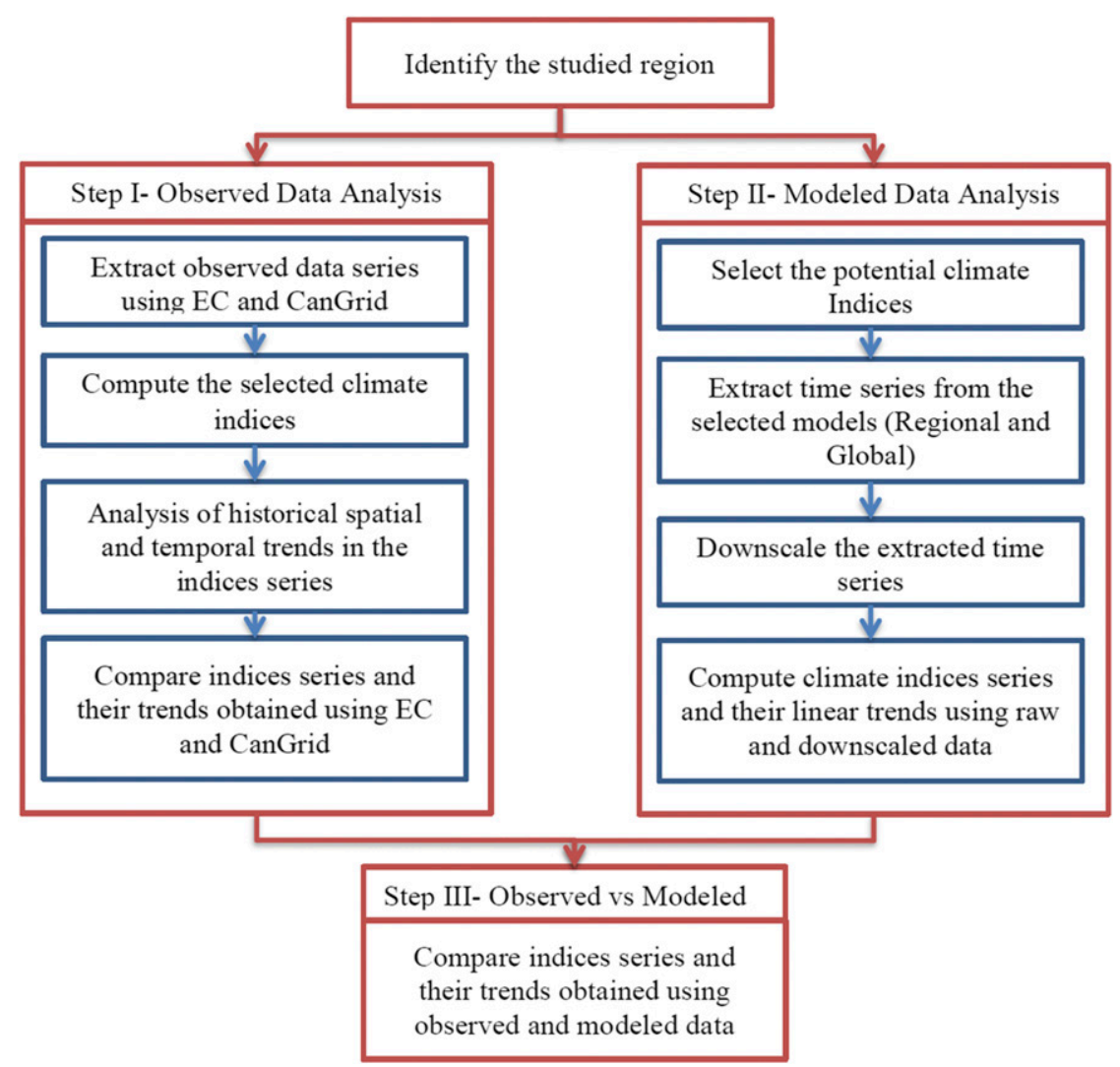

FIG. 2. An overview and major steps of the study method $(\mathrm{EC}=\mathrm{ECCC})$.

\section{f. Interpolation method}

To show the spatial variability of extreme climate indices, many interpolation methods have been developed and used in climatological studies (Hofstra et al. 2008). The performance of these methods depends on the geographic region under consideration, as well as the desired spatial scale of the analysis (Vicente-Serrano et al. 2003). In this study, the IDW method was used following Jones et al. (1986). The main assumption in IDW is that the interpolated values are influenced most by the nearby values and less by the distant observations. Therefore, the values derived by the IDW method are linear combinations of sampled values weighted by an inverse function of the distance between the sample and prediction points.

\section{g. Performance criteria}

To assess and compare the performance of climate models (i.e., CanRCM and GCMs) for the simulation of the observed climate indices and their related trends, two different categories of performance criteria are used: 1) criteria evaluating the ability of climate models to simulate the observed indices and 2) criteria evaluating the consistency of trends obtained using observed and climate models datasets. Further details are given below.
If the study area contains $G$ number of sites (or grids) and $I^{\mathrm{Ref}}$ and $I^{\mathrm{Mod}}$ are the climate indices obtained using observed (reference) and modeled datasets (RCM or GCM), then these indices can be written as

$$
\begin{aligned}
I_{g, t}^{\mathrm{Ref}} & =a_{g}^{\mathrm{Ref}} t+b_{g}^{\mathrm{Ref}} \quad \text { and } \quad I_{g, t}^{\mathrm{Mod}}=a_{g}^{\mathrm{Mod}} t+b_{g}^{\mathrm{Mod}} ; \\
g & =1, \ldots, G ; \quad t=T, T+1, \ldots, T+N,
\end{aligned}
$$

where $t$ is the time index and $a_{g}^{\text {Ref }}$ and $a_{g}^{\text {Mod }}$ are the linear trends in the index $I$ at the site $g$ between $T$ and $T+N$ years using reference and model datasets, respectively. Suppose that $\bar{I}_{t}^{\mathrm{Ref}}$ and $\bar{I}_{t}^{\mathrm{Mod}}$ are the averages of indices at the year $t$ across the entire study region:

$$
\bar{I}_{t}^{\mathrm{Ref}}=\frac{\sum_{g=1}^{G} I_{g, t}^{\mathrm{Ref}}}{G} \quad \text { and } \quad \bar{I}_{t}^{\mathrm{Mod}}=\frac{\sum_{g=1}^{G} I_{g, t}^{\mathrm{Mod}}}{G} .
$$

To evaluate the ability of climate models to simulate the observed indices, two average indices, $\bar{I}_{t}^{\mathrm{Ref}}$ and $\bar{I}_{t}^{\mathrm{Mod}}$, are compared by computing the following three skill scores:

1) The standard deviation, $\sigma_{\bar{I}^{\text {Ref }}}$, is defined for the average reference indices $\bar{I}_{t}^{\text {Réf }}$ over the $N$ years as 


$$
\sigma_{\bar{I}_{t}^{\mathrm{Ref}}}=\sqrt{\frac{\sum_{t=T}^{T+N}\left(\bar{I}_{t}^{\mathrm{Ref}}-\overline{\bar{I}}^{\mathrm{Ref}}\right)^{2}}{N}} \text { where } \quad \overline{\bar{I}}^{\mathrm{Ref}}=\frac{\sum_{t=T}^{T+N} \bar{I}_{t}^{\mathrm{Ref}}}{N} .
$$

A model has a good ability to simulate a reference index $I$ if the standard deviation $\sigma_{\bar{I}^{\text {Mod }}}$ of $\bar{I}_{t}^{\text {Mod }}$ is close to the standard deviation $\sigma_{\bar{I}_{t}^{\text {Ref }}}$ of $\bar{I}_{t}^{\text {Ref }}$.

2) The centered root-mean-square error (RMSD) between $\bar{I}_{t}^{\mathrm{Ref}}$ and $\bar{I}_{t}^{\mathrm{Mod}}$ is defined as

$$
\mathrm{RMSD}=\sqrt{\frac{\sum_{t=T}^{T+N}\left[\left(\bar{I}_{t}^{\mathrm{Ref}}-\overline{\bar{I}}^{\mathrm{Ref}}\right)-\left(\bar{I}_{t}^{\mathrm{Mod}}-\overline{\bar{I}}^{\mathrm{Mod}}\right)\right]^{2}}{N} .}
$$

A good model is expected to have a small RMSD value.

3) The Pearson correlation $R$ between $\bar{I}_{t}^{\mathrm{Ref}}$ and $\bar{I}_{t}^{\mathrm{Mod}}$ is defined as

$$
R=\frac{1}{N} \frac{\sum_{t=T}^{T+N}\left(\bar{I}_{t}^{\mathrm{Ref}}-\overline{\bar{I}}^{\mathrm{Ref}}\right)\left(\bar{I}_{t}^{\mathrm{Mod}}-\overline{\bar{I}}^{\mathrm{Mod}}\right)}{\sigma_{I}^{\mathrm{Ref}} \sigma_{I}^{\mathrm{Mod}}} .
$$

A good model must have a high $R$ value.

To show $\sigma$, RMSD, and $R$ together, and to compare several models, Taylor diagrams were used (Taylor 2001). This diagram uses the geometric and algebraic relationship between $R, \sigma$, and RMSD to compare the "distance" of a modeled value with the observations and its relation to other models.

To evaluate the consistency of the trend distribution obtained using observed and modeled datasets, the Kolmogorov-Smirnov (KS) statistics are used (Massey 1951). Suppose that $a_{1}^{\mathrm{Ref}}, \ldots, a_{G}^{\mathrm{Ref}}$ are the linear trends in index $I$ for $G$ number of sites using observed data and also that $a_{1}^{\mathrm{Mod}}, \ldots, a_{G}^{\mathrm{Mod}}$ are those using modeled data. The two-sample KS statistics evaluate the differences between the probability density functions (pdfs) of these two sample data vectors, and vary between 0 , which means that the trends in the indices computed using observed and modeled data are similar (i.e., they have the same pdf), and 1, which means that the trends are totally different (i.e., they have different pdfs).

\section{Results}

\section{a. Analysis of temporal and spatial trends}

\section{1) TEMPORAL TRENDS}

Time series of precipitation indices computed using ECCC weather station and CanGrid data from 1960 to
2013 are shown in Fig. 3, along with their average values over the study area. Summary statistics of these averages are given in Table 4. We found the lowest total annual precipitation value of $725 \mathrm{~mm}$ at the Billy Bishop Toronto City Airport (which is also known as the Toronto Island Airport) and the highest annual precipitation of $1162 \mathrm{~mm}$ at the Dwight station, which is located near Algonquin National Park in the northern part the study region. Toronto Island Airport experienced the maximum number of CDD, minimum number of CWD and minimum PRCPTOT amount. Toronto Island Airport is located on a small island in Lake Ontario near downtown Toronto. At this location, wind flow and day and night heating/cooling patterns are different from areas located farther inland. Onshore wind speed is generally higher and cooler (or warmer in late autumn) as a result of the influence of Lake Ontario's water. This may have contributed to lower precipitation at this location. The area around Dwight has higher elevation ( $400 \mathrm{~m}$; Table 1) and much more forest cover. Weather patterns in this area are more influenced by Lake Huron because of its proximity to the Georgian Bay region in the west. These regional influences may have contributed to higher precipitation in this part of the study area. Overall, we found that the regional averages of indices derived using the ECCC and CanGrid data sources are very well correlated, having correlation coefficient $\left(R^{2}\right)$ values of 0.80 and 0.98 , respectively.

The trends in the precipitation indices computed using the ECCC weather station and CanGrid data and their relative errors are shown in Fig. 4. Summary statistics [mean and relative standard deviation (RSD)] of trends and their MK significance test results are given in Table 5. RSD was estimated (by dividing the absolute standard deviation by the absolute mean of trends) to describe the range of interstation variability among these indices, and to quantify the representativeness of average trend values. For specific indices, a small RSD value means lower interstation variability in average trend and proper representation of the climate of the area or vice versa. Using ECCC data, we found that 1) PRCPTOT showed a significant positive trend in $65 \%$ of the stations with a regional average (i.e., average over all stations) value of $30 \mathrm{~mm}$ decade $^{-1}$, 2) R99p showed a significant positive trend at $18 \%$ stations and a regional average value of $4.75 \mathrm{~mm}$ decade $^{-1}$, 3) CDD showed a significant negative trend at $19 \%$ of the stations and a regional average of -0.5 days $\mathrm{yr}^{-1}$, and 4) CWD had a significant negative trend at $42 \%$ of the stations and a regional average of 0.30 days $\mathrm{yr}^{-1}$ (Table 5). A comparison of trends in indices computed using ECCC data with CanGrid data showed similar patterns $\left(R^{2}\right.$ values ranging between 0.5 and 0.65 ); however, CanGrid generally 


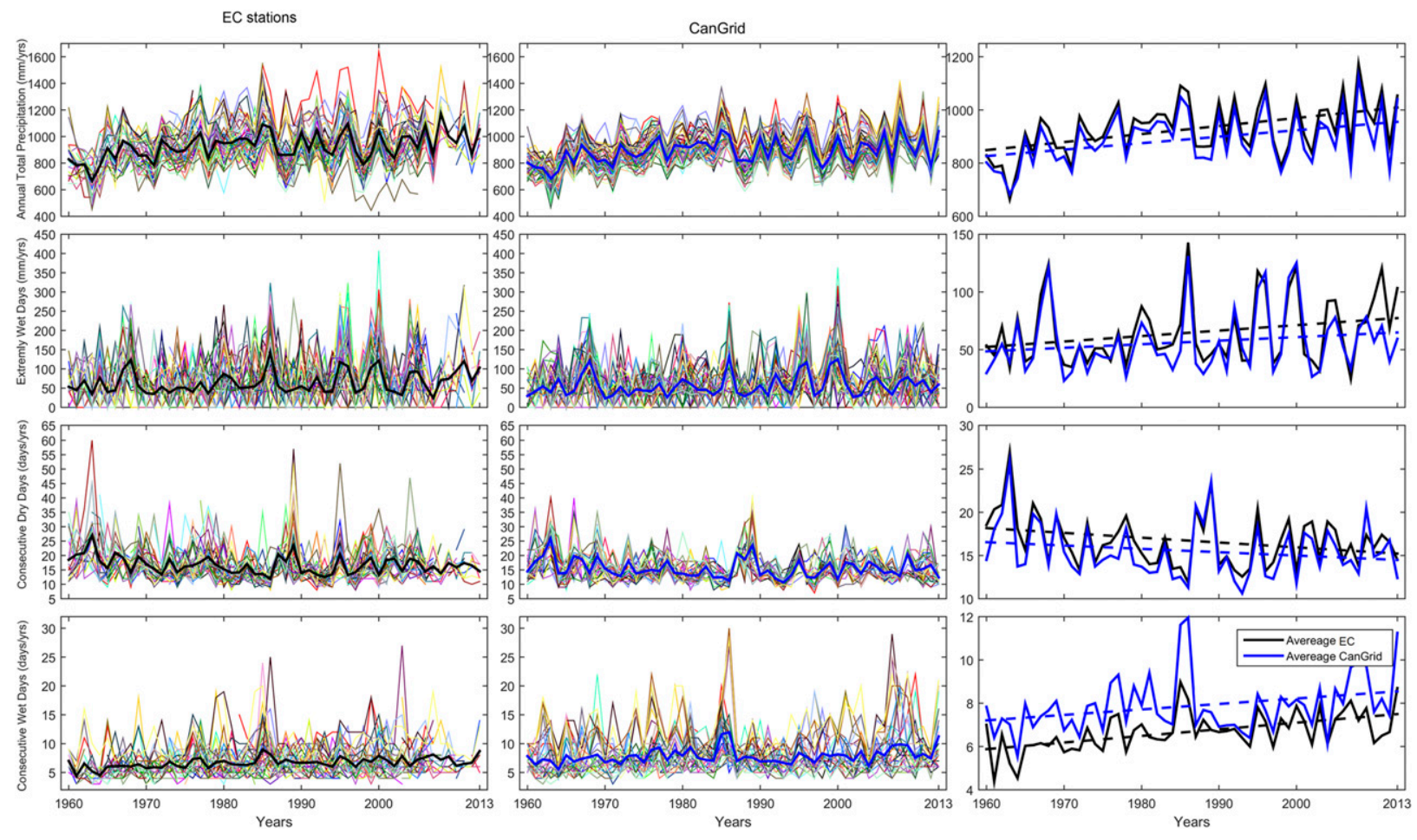

FIG. 3. Time series of PRCPTOT, R99p, CDD, and CWD indices computed using ECCC weather station and CanGrid data from 1961 to 2013. (left) The solid black lines represent the average indices computed using ECCC weather station data. (center) The solid blue lines represent the averages of indices computed using CanGrid data. (right) Comparison between the average ECCC and CanGrid indices across the study area. The dashed lines in the right column represent the linear trends in the averages of the indices. For each of these indices, there is a single value for each year and station. Therefore, each curve represents the index series at a station during the study period. The lack of ECCC data in some years and at certain stations results in some of these curves being incomplete.

exhibited an underestimation of precipitation (Fig. 4). This underestimation can be caused by the interpolation technique applied on the station data used to derive the CanGrid dataset. CanGrid data underestimated the variability in natural climate indices, as shown by higher RSD values (Table 5). We observed a high variability in interstation trends for precipitation indices that described intense precipitation and dry and wet periods. This can be caused by the high spatial variability in the precipitation and evapotranspiration processes in the region as a result of its proximity of the Great Lakes, built-up urban areas, and large-scale moisture transport in the region due to westerly and moisture-laden warm southern winds. Thus, the spread around the ensemble

TABLE 4. Summary statistics and comparison of climate indices computed using observed data from 48 weather stations (ECCC) and CanGrid data. The right column represents the correlations between the averages of indices computed using ECCC and CanGrid datasets.

\begin{tabular}{|c|c|c|c|c|c|c|c|}
\hline \multirow[b]{3}{*}{ Index } & \multicolumn{6}{|c|}{ Statistics } & \multirow{3}{*}{$\frac{\text { Comparison }}{\text { Correlation coef }\left(R^{2}\right)}$} \\
\hline & \multicolumn{3}{|c|}{ Min } & \multicolumn{3}{|c|}{ Max } & \\
\hline & ECCC & CanGrid & $\overline{\text { Site ID }}$ & ECCC & CanGrid & $\overline{\text { Site ID }}$ & \\
\hline PRCPTOT $\left(\mathrm{mm} \mathrm{yr}^{-1}\right)$ & 724.85 & 779 & 42 & 1162.60 & 1040.60 & 7 & 0.98 \\
\hline $\mathrm{R} 99 \mathrm{p}\left(\mathrm{mm} \mathrm{yr}^{-1}\right)$ & 48.80 & 46.40 & 46 & 75.11 & 64.29 & 40 & 0.88 \\
\hline CDD (days $\mathrm{yr}^{-1}$ ) & 13.96 & 13.77 & 7 & 21.15 & 18.25 & 42 & 0.93 \\
\hline CWD (days yr ${ }^{-1}$ ) & 5.04 & 5.09 & 42 & 10.25 & 12.83 & 30 & 0.80 \\
\hline TX10p (days yr ${ }^{-1}$ ) & 7.45 & 9.50 & 18 & 11.30 & 10.37 & 19 & 0.98 \\
\hline TN90p (days $\mathrm{yr}^{-1}$ ) & 9.74 & 10.16 & 26 & 12.20 & 11.23 & 22 & 0.99 \\
\hline $\mathrm{TNn}\left({ }^{\circ} \mathrm{C}_{\mathrm{yr}^{-1}}\right)$ & -35.81 & -35.85 & 7 & -19.60 & -20.16 & 43 & 0.98 \\
\hline 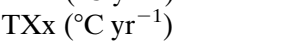 & 29.84 & 30.26 & 35 & 34.34 & 34.22 & 19 & 0.99 \\
\hline
\end{tabular}



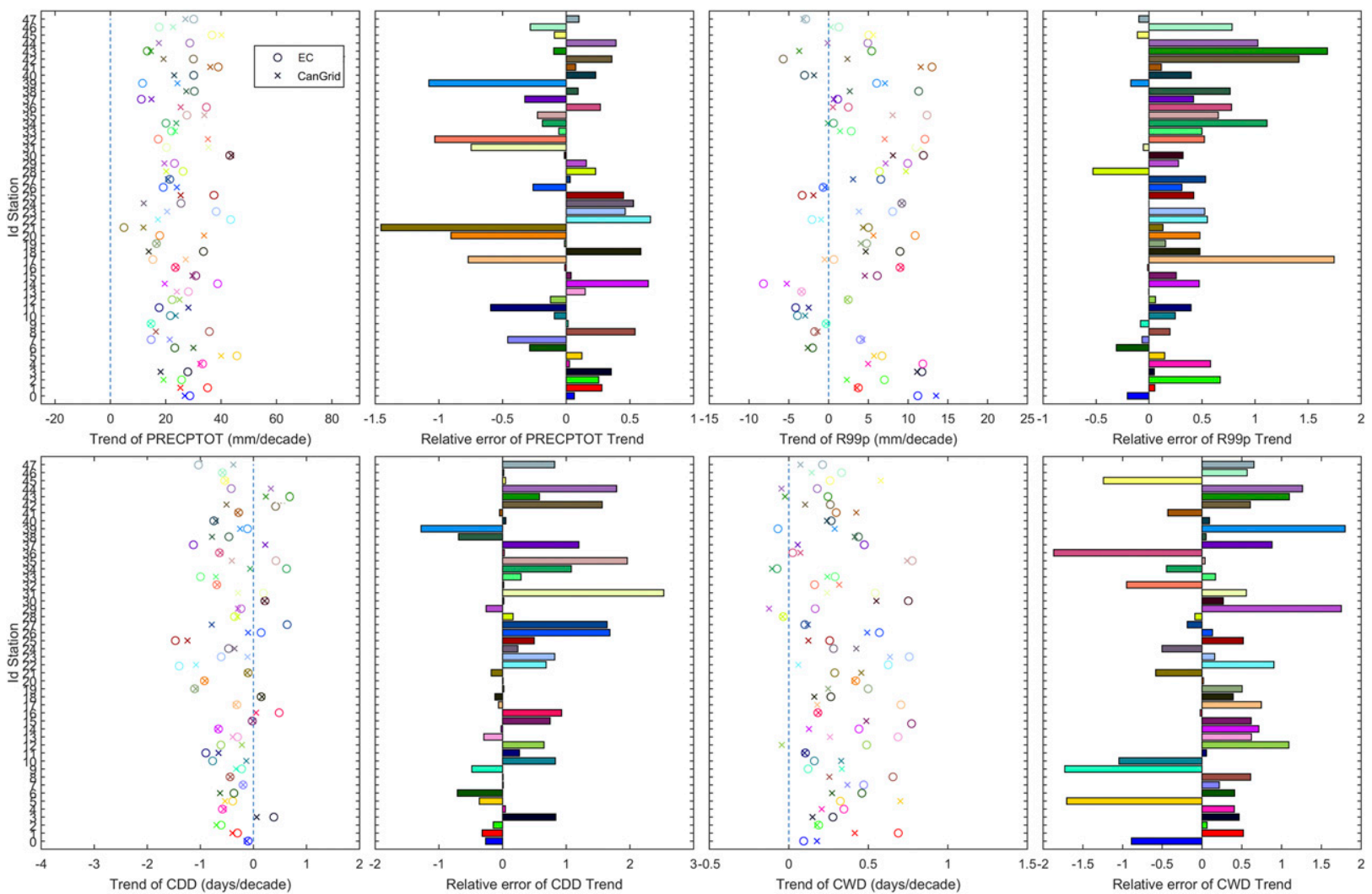

FIG. 4. Trends of indices computed using ECCC weather station and CanGrid data and their relative errors for PRECPTOT, R99p, CDD, and CWD for 1961-2013. Open circles represent the observed data trends and bars represent the CanGrid trends.

station average of these indices appears large (high RSD value) and the ensemble average does not adequately represent the precipitation trends in the area.

The time series of temperature indices are shown in Fig. 5, computed using ECCC (left column) and CanGrid (center column) data over the 1961-2013 period. The averages of these indices across all stations are shown in the right column in Fig. 5. The results presented in Fig. 5 are summarized in Table 4. In terms of the average over the study period, for temperature indices, we found that the two stations Dwight and Proton have the minimum values of daily minimum and daily maximum temperatures, respectively. These two stations are located in rural areas at high elevations. The highest warming is recorded in urban centers close to the Great Lakes. In term of comparison, temperature indices using ECCC and CanGrid data matched very well for almost all of the years and are

TABLE 5. Average and relative standard deviation (RSD) of trends and the MK significance percentages computed using observed data from 48 weather stations (ECCC) and CanGrid data. The last column represents the correlation between the trends computed using ECCC and CanGrid datasets.

\begin{tabular}{|c|c|c|c|c|c|c|c|}
\hline \multirow[b]{2}{*}{ Index } & \multicolumn{3}{|c|}{ ECCC } & \multicolumn{3}{|c|}{ CanGrid } & \multirow{2}{*}{$\frac{\text { Comparison }}{\text { Correlation coef }\left(R^{2}\right)}$} \\
\hline & Significance (\%) & Avg decade ${ }^{-1}$ & $\mathrm{RSD} / \%$ & Significance (\%) & Avg decade ${ }^{-1}$ & $\mathrm{RSD} / \%$ & \\
\hline PRCPTOT (mm) & 65 & 30.20 & 38 & 85 & 24.30 & 30 & 0.58 \\
\hline $\mathrm{R} 99 \mathrm{p}(\mathrm{mm})$ & 18 & 4.75 & 85 & 20.8 & 3.08 & 78 & 0.61 \\
\hline CDD (days) & 17 & -0.55 & 74 & 15 & -0.38 & 68 & 0.51 \\
\hline CWD (days) & 32 & 0.30 & 79 & 30 & 0.25 & 72 & 0.53 \\
\hline TX10p (days) & 90 & -1.23 & 30 & 100 & -1.08 & 16 & 0.50 \\
\hline TN90p (days) & 85 & 1.02 & 41 & 100 & 1.24 & 26 & 0.65 \\
\hline $\mathrm{TNn}\left({ }^{\circ} \mathrm{C}\right)$ & 75 & 0.61 & 43 & 85 & 0.70 & 27 & 0.50 \\
\hline $\mathrm{TXx}\left({ }^{\circ} \mathrm{C}\right)$ & 40 & 0.21 & 44 & 45 & 0.22 & 34 & 0.51 \\
\hline
\end{tabular}



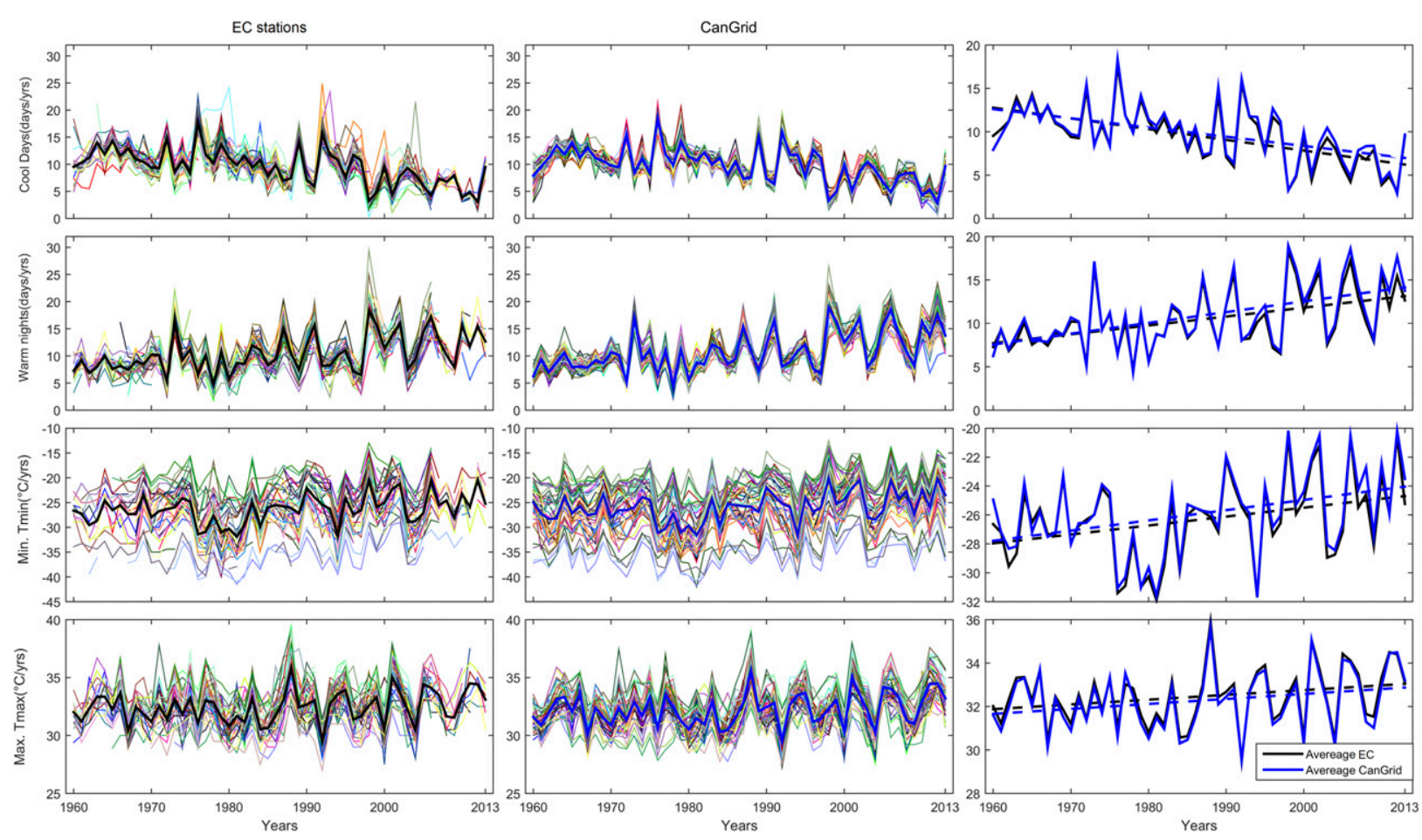

FIG. 5. Time series of TX10p, TN90p, TNn, and TXx indices computed using ECCC weather station and CanGrid data from 1961 to 2013. (left) The solid black lines represents the average indices computed using ECCC weather station data. (center) The solid blue lines represent the averages of indices computed using CanGrid data. (right) A comparison between the average ECCC and CanGrid indices across the study area. The dashed lines in the right column represent the linear trends in the averages indices.

very well correlated, as was the case for precipitation indices.

The trends in the temperature indices computed using ECCC weather station and CanGrid data and their relative errors are shown in Fig. 6. Summary statistics of trends and MK significance test results are summarized in Table 5. In terms of trend values using ECCC data, we found that 1) TX10p showed a significant negative trend in $90 \%$ of the stations, with a regional average value of -1.2 days decade $^{-1}$; 2) TN90p showed a significant positive trend in $85 \%$ of the stations, with a regional average value of 1 day decade ${ }^{-1}$; 3) TNn showed a significant positive trend in $75 \%$ of the stations, with a regional average of $0.6^{\circ} \mathrm{C}$ decade $^{-1}$; and 4) TXx exhibited a significant positive trend in $40 \%$ of stations, with a regional average of $0.2^{\circ} \mathrm{C} \mathrm{decade}^{-1}$. Similar trends were found while using CanGrid data. Comparison of TX10p with TN90p, including RSD values, indicated that the interstation variability of the minimum temperature was greater than that for the maximum temperature. Overall, warming in the minimum temperature was almost 2 times than the magnitude for the maximum temperature.

In summary, we found a consistent increasing trend in the daily temperature extremes. The number of extremely cold days decreased and the number of hot nights increased. Moreover, hot extremes generally showed higher values than their cold counterparts. Precipitation indices showed an increasing trend in annual total precipitation and extremely wet days and a decreasing trend in extremely dry days. Overall, precipitation indices had higher interstation variability than those of temperature indices, which is logical because of the high spatial variability of precipitation processes in the regions as compared with temperature.

\section{2) SPATIAL TRENDS}

Results described in the previous section show a good level of agreement between the ECCC and CanGrid datasets. Therefore, we used CanGrid as the observed dataset to compute the spatial variability in climate indices. Spatial variability of trends in precipitation indices and corresponding $p$ values from the MK significance test (calculated after verification of the required independent assumption) are shown in Fig. 7. These results are summarized in Table 6. We observed a positive trend in PRCPTOT that varies between 1.5 and $38 \mathrm{~mm}$ decade $^{-1}$, with an average of $17 \mathrm{~mm}$ decade $^{-1}$ across the study area. The smallest trends in PRCPTOT were found in the Halton, Toronto, Peel, York, Leeds Grenville, Simcoe, and Muskoka areas of Ontario. The largest trends were found in Bruce, Grey, and Haliburton 

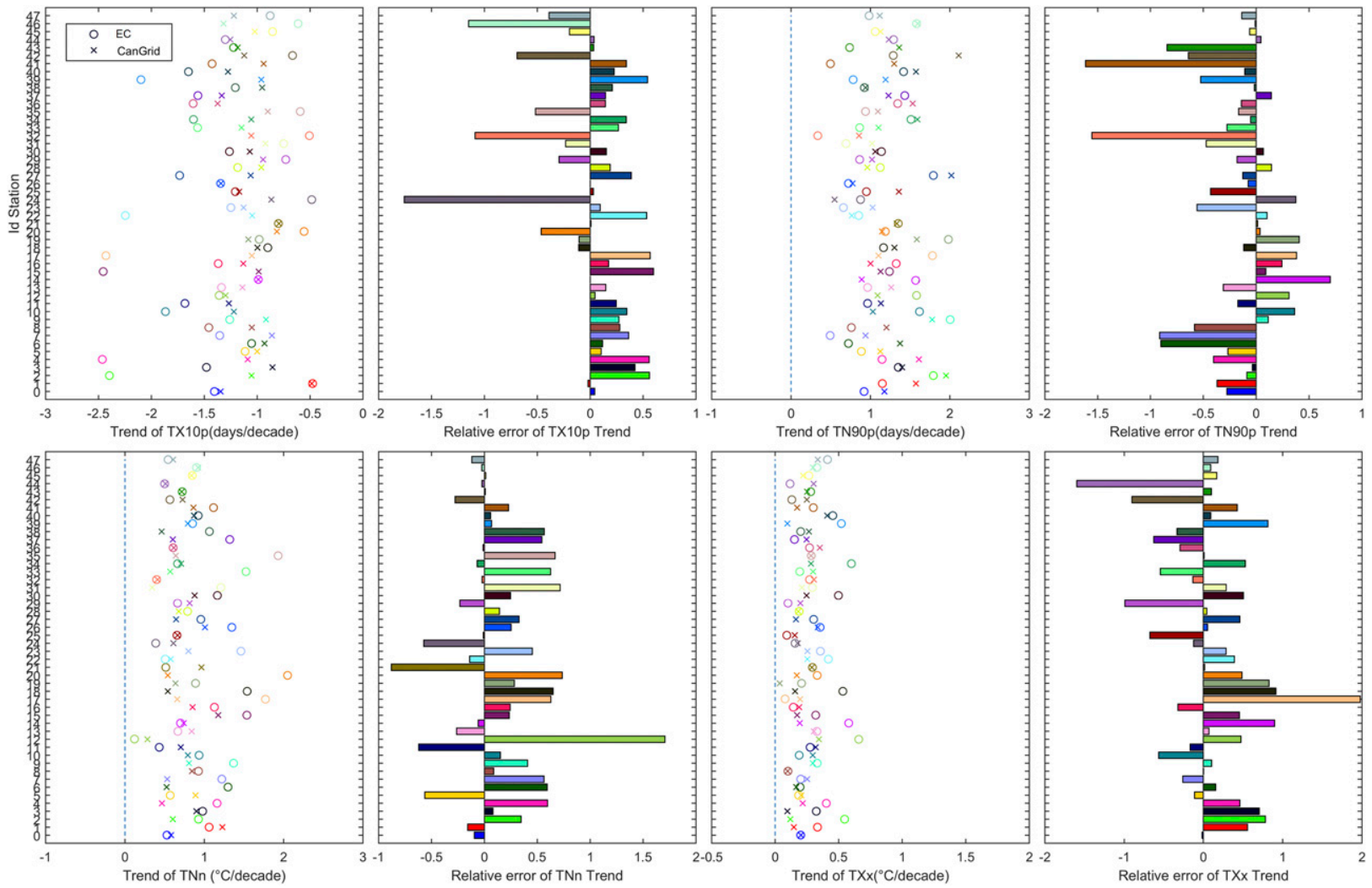

FIG. 6. Trends of indices computed using ECCC weather station and CanGrid data and their relative errors for TX10p, TN90p, TNn, and TXx for 1961-2013. Open circles represent the observed data trends and bars represent the CanGrid data.

Counties. PRCPTOT trends showed significant $p$ values in $61.5 \%$ of the area and they were more significant in the eastern and central parts of the study area. Values of R99p showed positive trends in $81.2 \%$ of the area and the results varied between -10 and $16 \mathrm{~mm}$ decade $^{-1}$, with an average of $3.6 \mathrm{~mm}$ decade $^{-1}$ across the study area. The negative trends in R99p were found in the Niagara, Hamilton, Halton, Peel, Toronto, and York areas. The highest R99p trends are found in the same areas as of the largest PRCPTOT trends. The R99p trends were significant in $35.3 \%$ of the region and they were more significant in the eastern parts. CDD had negative trends in $96.5 \%$ of the area and ranged from -1.2 to 0.13 days decade ${ }^{-1}$, with an average of -0.4 days decade ${ }^{-1}$ across the study area. The highest CDD trends are observed in the western parts of the study area. Finally, CWD had positive trends in $90.1 \%$ of the area and ranged between -0.13 and 0.9 days decade $^{-1}$, with an average of 0.25 days decade $^{-1}$ across the study area. The CWD trends were significant in $36.7 \%$ of the study area, especially in the northern parts. Changes in CWD trends may be of more concern than those in CDD because they indicate whether an area is experiencing more extreme precipitation. It may be particularly important where people are living in floodprone areas and where most agricultural activity takes place. Our study results indicate that the annual total precipitation and the frequency of extreme precipitation events are expected to increase in the most parts of the study area (i.e., more wet days and fewer dry days).

The spatial variability of the trends in temperature indices across the study region is shown in Fig. 8 and summarized in Table 6. For TX10p, we showed negative trends that varied between -0.8 and 0 days decade ${ }^{-1}$, with an average of -0.4 days decade ${ }^{-1}$. The highest negative trends was observed in the Essex, Elgin, Niagara, Halton, Peel, Toronto, and Northumberland areas, while the lowest were found in Huron, Grey, Simcoe, and Muskoka. The TX10p trends were significant in $64.5 \%$ of the study area and especially in the central and western parts of the region. We also observed significant positive trends in the TN90p indices in the area that ranged between 0.5 and 1.75 days decade ${ }^{-1}$, with an average value of 1 day decade ${ }^{-1}$. The highest positive TN90p trends are found in the same area as were observed for the lowest TX10p trends. The TNn trends were generally positive in $98.5 \%$ of the study area, which varied between $-0.25^{\circ} \mathrm{C}$ and $0.9^{\circ} \mathrm{C} \mathrm{decade}^{-1}$, 

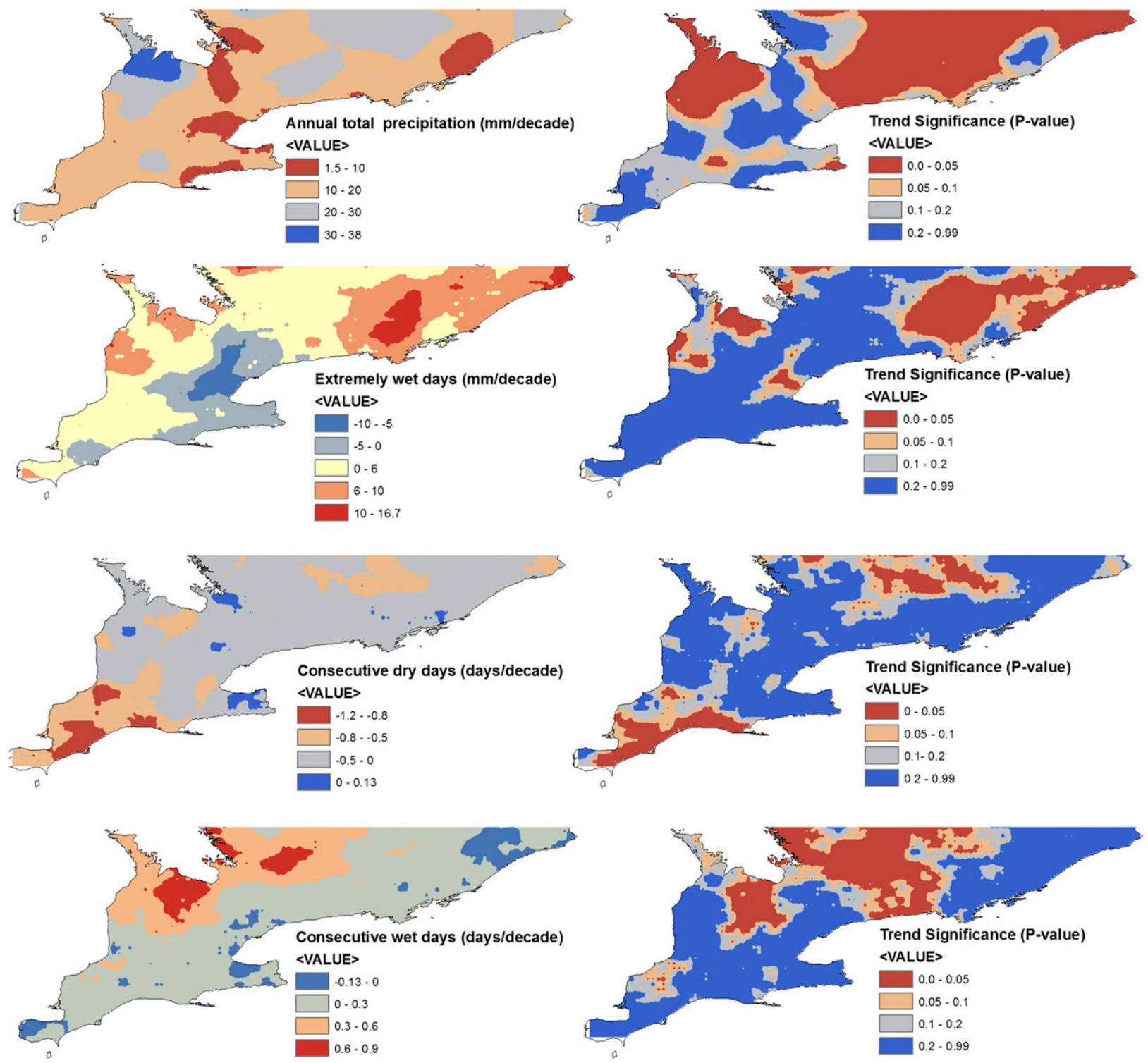

FIG. 7. (left) Spatial variability of trends in precipitation indices from 1951 to 2013 using data from 1969 grids of CanGrid data in the study area. (right) The $p$ values of the MK significance test.

with an average value of $0.3^{\circ} \mathrm{C}$ decade ${ }^{-1}$. The highest $\mathrm{TNn}$ trends were found in the Huron, Simcoe, and Ottawa districts. The TNn trends were significant in $32.5 \%$ of the area. There was a positive significant trend in TXx in $25.3 \%$ of the area, and trend values varied between $-0.5^{\circ} \mathrm{C}$ and $0.4^{\circ} \mathrm{C}$ decade ${ }^{-1}$, with an average of $0.1^{\circ} \mathrm{C}$ decade $^{-1}$. Therefore, the minimum and maximum temperatures are expected to increase with a greater increase in the minimum rather than in the maximum temperature $\left(0.3^{\circ}\right.$ vs $0.1^{\circ} \mathrm{C}$ decade $\left.^{-1}\right)$. As a result, the nighttime warming estimated using average daily minimum temperatures had been slightly greater than daytime warming, which was estimated from average daily maximum temperatures. The frequency of cold temperature extremes is projected to decrease (fewer cold days), while the frequency of warm extremes is expected to increase (more warm nights). Overall, we observed a low spatial variability in the temperature indices.

In summary, PRCPTOT and R99p showed no significant trends in the southwest and central parts of Ontario. The highest CWD trends were found close to Georgian Bay. Changes in precipitation extremes were in general spatially more complex and locally less significant than temperature indices. For temperature indices, TN10p and TN90p had significant trends in more than $90 \%$ of the 
TABLE 6. Summary statistics and significance (\%) of trends in the climate indices computed using CanGrid data at 1699 grids in the study area. Significance is defined as the number of grid points that exhibit statistically significant trends divided by the total number of grid points.

\begin{tabular}{|c|c|c|c|c|}
\hline Indices & Min & Max & Avg & Significance (\%) \\
\hline PRCPTOT (mm decade ${ }^{-1}$ ) & 1.5 & 38 & 17 & 61.5 \\
\hline R99p (mm decade $\left.{ }^{-1}\right)$ & -10 & 16 & 3.6 & 35.3 \\
\hline CDD (days decade ${ }^{-1}$ ) & -1.2 & 0.13 & -0.40 & 26.0 \\
\hline CWD (days decade ${ }^{-1}$ ) & -0.13 & 0.90 & 0.25 & 36.7 \\
\hline TX10p (days decade ${ }^{-1}$ ) & -0.80 & 0 & -0.40 & 100 \\
\hline TN90p (days decade ${ }^{-1}$ ) & -0.50 & 1.75 & 1 & 64.5 \\
\hline $\mathrm{TNn}\left({ }^{\circ} \mathrm{C}\right.$ decade $\left.^{-1}\right)$ & -0.25 & 0.90 & 0.30 & 32.5 \\
\hline TXx $\left({ }^{\circ} \mathrm{C}\right.$ decade $\left.{ }^{-1}\right)$ & -0.50 & 0.40 & 0.10 & 35.4 \\
\hline
\end{tabular}

study area. The increase in maximum temperature was more pronounced in the high-altitude regions.

\section{b. Comparison of observed and modeled data}

To identify the robust climate model that can be used to reproduce the historically observed climate indices and their trends in this region, daily temperature and precipitation time series were extracted and analyzed for all 1969 grids $(\sim 10-\mathrm{km}$ resolution) in the study area using CanRCM4 (40-km grid resolution) and three GCMs from CMIP5 [i.e., CanESM2, CCSM4, and CESM1(BGC) (100-km grid resolution)]. Average precipitation indices across all 1969 grids over the 1951-2013 period are shown in Fig. 9. Comparison of observed average indices (CanGrid) and the modeled ones in terms of RMSD and the Pearson correlation is shown in Table 7. Plots of the full range of precipitation indices for each individual model are given in Figs. S1-S4 in the online supplement to this paper. In general, we found more wet days and fewer dry days using CanRCM4 and CanESM2 model data, when compared with CanGrid (see time series of Consecutive Wet Days and Consecutive Dry Days). The Pearson correlation and RMSD values indicated that C-CCSM4 (corrected CCSM4) was able to reproduce observed the PRCPTOT, R99p, and CWD indices quite well. However, CDD was better reproduced by CanRCM4. Although, no model performed well for all four indices, C-CCSM4 (model F) generally simulated the average precipitation indices well. We also found that bias correction improved the model's ability to accurately simulate observed precipitation indices [i.e., models after bias correction were closer to the reference (i.e., CanGrid) in the Taylor diagram than before bias correction].

Figure 10 shows the average temperature indices across the study region, and their corresponding Taylor diagrams with time series of temperature indices for all four models are given in Figs. S1-S4 in the online supplement. Generally, we found higher TNn and TXx values using CanRCM4 and CanESM2 models as compared with CanGrid. According to the correlation criterion (Table 7), CanESM2 again was able to reproduce the observed TX10p, TN90p, and TNn trends reasonable well, while C-CanESM2 (corrected CanESM2) was able to simulate the observed TXx index well, as shown in Table 7. Although, it was difficult to choose one best model for all four temperature indices, CCSM4 (model E) performed reasonably well in simulating the observed temperature indices.

The pdfs of the linear trends in the climate indices computed using CanGrid and the climate model are shown in Fig. 11. Generally, similar trend signs were found for climate indices for the observed (CanGrid) and modeled data. Table 7 summarizes the KS values obtained for the different models, where a KS value close to 0 means the pdfs of the model and reference trends are similar. We found that 1) C-CanRCM4 (corrected CanRCM4) reproduced the observed linear trends in PRCPTOT, CDD, TX10p, TNn, and TXx quite well; 2) CanRCM4 reproduced the observed trends in R99p well; and 3) CCSM4 reproduced the observed trends in the CWD and TN90p indices reasonably well. We also found that the KS distances between the reference and the corrected model are smaller than those with raw model data, which means that bias correction improved the ability of the model data to simulate the linear trends in the observed climate indices.

In summary, we found that the CanRCM4 model was able to reproduce historically observed trends in the climate indices reasonably well as compared with GCMs. This is mostly because of the fine spatial scale of the model and/or its ability to better simulate precipitation and temperature processes in the region.

\section{Discussion}

In this study observed and modeled temperature and precipitation indices were compared to provide a 

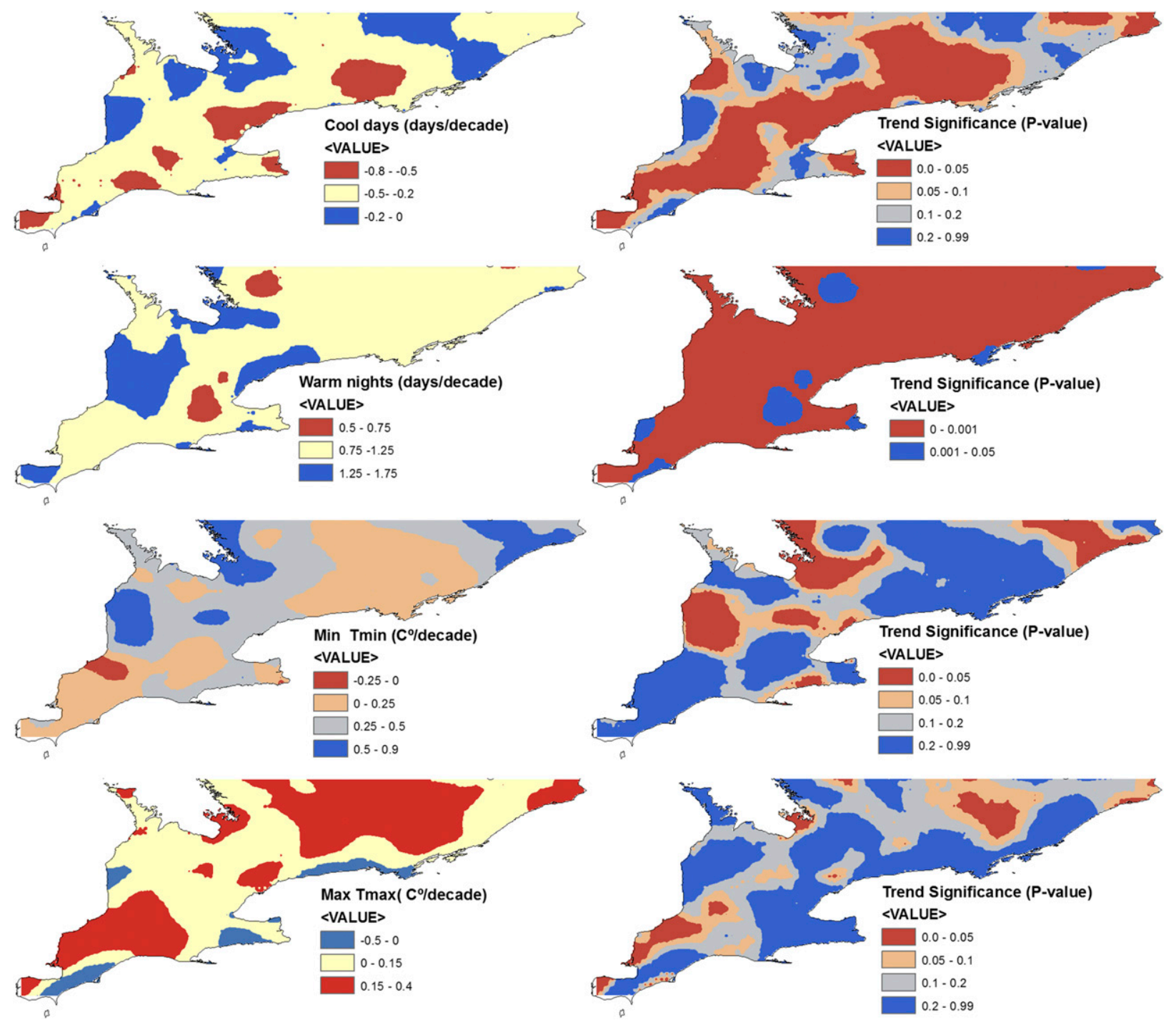

FIG. 8. As in Fig. 7, but for temperature indices.

comprehensive analysis of historical climate trends and their uncertainty in southern Ontario, Canada. Although many studies have been conducted to analyze climate trends in the region (e.g., Adamowski et al. 2010; Mohsin and Gough 2010; Razavi et al. 2016), the main focus of our study was on providing a detailed overview and a deeper understanding of the variation of extreme weather frequency and intensity at the local scale. In addition our study is the first to cover this entire region.

Our analysis results are consistent with previous studies reported in the literature, indicating an increasing trend in the annual total precipitation of about $5 \%-35 \%$, and mean annual air temperature increase of about $1.5^{\circ} \mathrm{C}$, but with fewer days with extreme low temperature and more days with extreme high temperature over the 1950-2010 period in Canada (e.g., Vincent et al. 2012;
Zhang et al. 2000). These past studies also showed that nighttime warming has been slightly greater than daytime warming. Vincent and Mekis (2006) reported more days with precipitation for the 1950-2003 period. DeBeer et al. (2016) showed a high spatial variability in the extreme precipitation trends and a strong spatial coherence in the extreme temperature trends. We found similar climate trends in the region, with $+105.3 \mathrm{~mm}$ for PRCPTOT, $+22.06 \mathrm{~mm}$ for R99p, -2.35 days for $\mathrm{CDD},+1.42$ days for $\mathrm{CWD},-2.52$ days for TX10p, +6.63 days for TN90p, $+1.91^{\circ} \mathrm{C}$ for $\mathrm{TNn}$, and $+0.86^{\circ} \mathrm{C}$ for TXx over the 1951-2013 period.

We found the highest trends in temperature indices in urban areas in the region. These trends in the temperature are linked to the increase in atmospheric greenhouse gases (Gillett et al. 2008; Wan et al. 2015; Zhang et al. 2006) as 

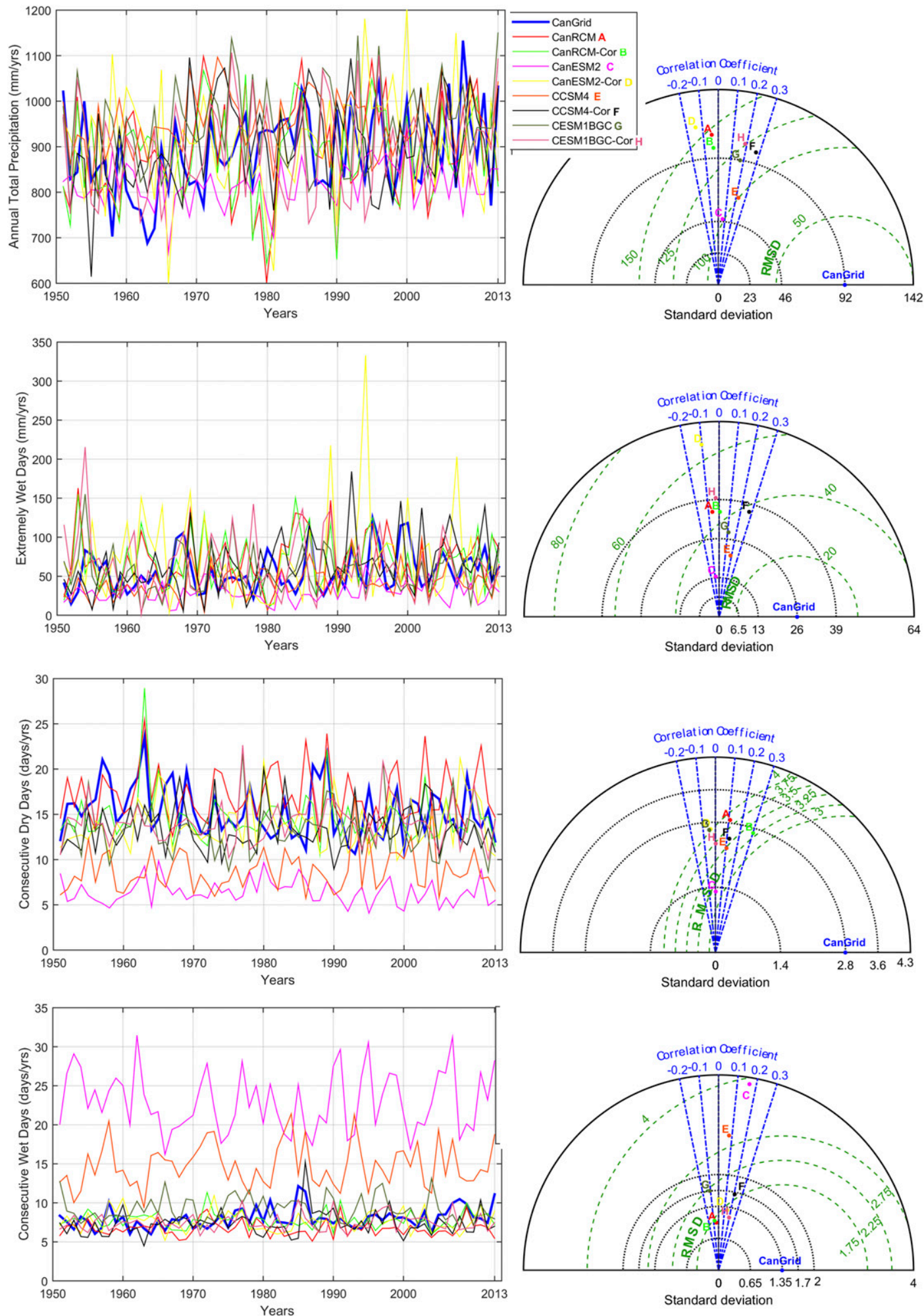

FIG. 9. Taylor diagrams showing the correlation between RCM- and GCM-simulated precipitation indices and observations (CanGrid) from 1951 to 2013. Black semicircles represent the magnitude of the standard deviation relative to the observed value. Green semicircles represent the RMSD error, and radial dashed blue lines indicate the correlation between the models and the observations. Circles with accompanying colored letters correspond to RCM and GCM models. A "best" model would be located at the square where the RMSD is minimum, the correlation coefficient is maximum, and the standard deviation is equal to the standard deviation of the observed model. 
well as the urban heat island effect (Karl et al. 1988). Urban heat islands are the result of numerous anthropogenic heat sources, changes in albedo and radiation balance, and decreased infiltration and evaporation due to built-up areas and the loss of forest cover (Gallo et al. 1996). Karl et al. (1988) suggested that temperature increases due to the heat island effect may change with population density, varying from $0.06^{\circ} \mathrm{C}$ for a population of $\sim 2000$ to $\sim 0.7^{\circ} \mathrm{C}$ for a population of 0.5 million. There are many cities in the region with large populations, which may have contributed to these warning trends.

Seasonal and annual climate variability in both temperature and precipitation in the Great Lakes region is also influenced by low-frequency climate oscillations such as El Niño-Southern Oscillation, the North Atlantic Oscillation, the Arctic Oscillation, the eastern Pacific Oscillation, and the Pacific-North American teleconnection (Li et al. 2010; Thorne and Arain 2015; Vincent et al. 2015). Other factors such as proximity to large water bodies for thermal moderation and lake-effect snow, along with regional storm systems causing large-scale moisture transport, may also be a factor in influencing the local climate in some years. These regional and local influences contribute to making the climate of the Great lakes region quite complex and add uncertainty to their predictions (Li et al. 2010; Thorne and Arain 2015).

Major environmental and economic impacts can be caused by the changes in extreme temperature and precipitation events in this densely populated and highly industrialized region. Warmer temperatures in this region will increase evaporation, which will likely result in a lowering of water levels in the Great Lakes, affecting the seasonal climate dynamics and water quality (Colombo et al. 2007). Moreover, changes in regional climate could affect the growth, distribution, and abundance of many vegetation species and impact the agriculture sector. Energy demand for heating and cooling may also be impacted as a result of changes in warm and cold/frost days (Bonsal et al. 2001).

In terms of comparison between indices obtained using CanGrid and ECCC, we showed that, for the southern part of Ontario, CanGrid underestimates the linear trends. Similar results are also reported by Hutchinson et al. (2009). In fact, by comparing the recorded and the estimated values over the southern part of Canada, Hutchinson et al. showed that the absolute interpolation errors in the CanGrid model for the annual mean were limited to $1.0^{\circ} \mathrm{C}$ for maximum temperature, $1.3^{\circ} \mathrm{C}$ for minimum temperature, and about $9 \%$ for annual precipitation, which can cause underestimation in climate indices.

In terms of comparison between indices obtained using CanGrid and global and regional model data, we 

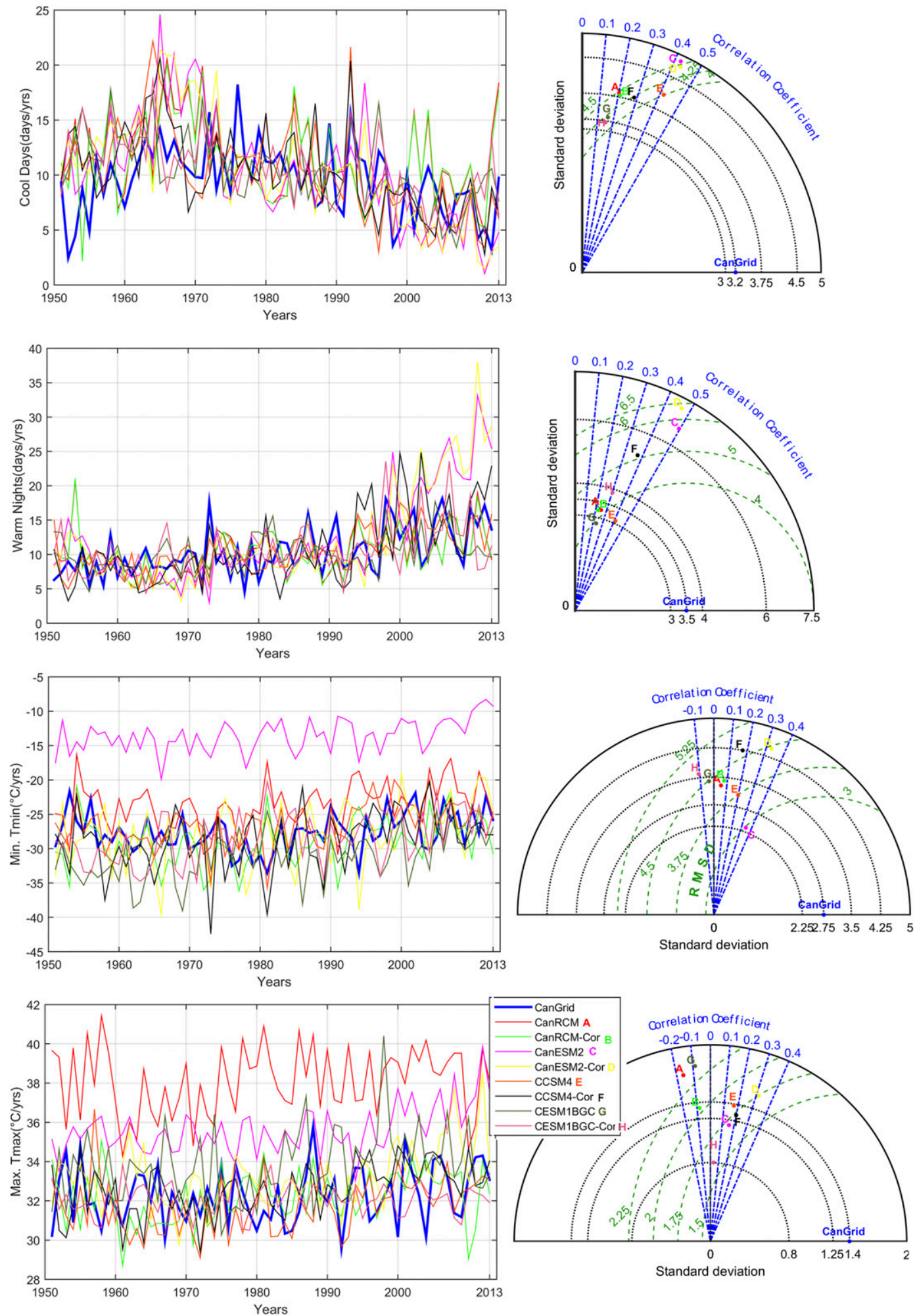

FIG. 10. As in Fig. 9, but for temperature indices. 

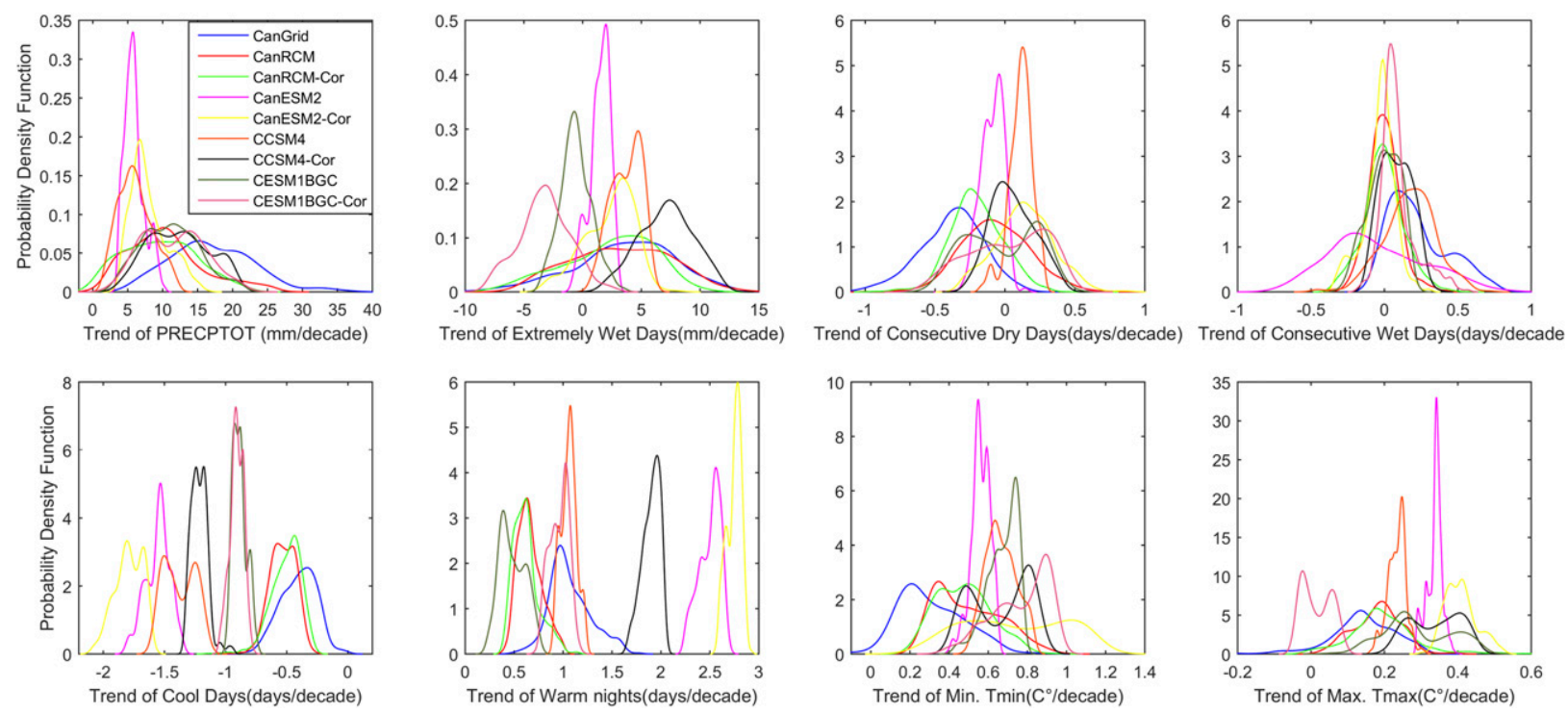

FIG. 11. The pdfs of the linear trends in the climate indices computed using observed and climate-model-simulated datasets. The blue curve represents the pdf of trends using observed data (i.e., the reference curve).

found that climate extremes estimated by CanRCM4 and CanESM2 are warmer and wetter than those estimated by CanGrid. Similar results were found by Whan and Zwiers (2016) for eastern Canada. Whan and Zwiers argue that the bias in the simulated data can be related to some model factors, such as physical parameterizations or uncertainties related to inadequate processes in the land surface schemes used in regional and global climate models. We found that the CanRCM4 model offers more refined simulations of the local climate (in terms of simulating the observed trends in climate indices). However, this model is driven by GCM boundary conditions and makes additional assumptions in its parameterization, which must be considered by the users (Razavi et al. 2016). In addition, changes in the temperature and precipitation may behave differently and the extreme events may be of different durations. This aspect should be considered in the baseline intensities of the extremes of different durations, when characterized using observed or modeled data (Lu et al. 2015a,b).

The main limitation of our study arises from the lack of seasonal analysis and trend analysis of future climate projections for different climate scenarios. A thorough sensitivity analysis of various impact factors would help to improve the results of this study. Such factors may include the interpolation methods used to compute spatial trends, as well as the bias-correction methods used to correct the GCM and RCM datasets. Another limitation of our study was the use of only three GCMs for the analysis among the available CMIP5 models. Three models cannot capture the full range of possible climate variability and therefore it can lead to large uncertainty in the results. Future work can focus on the analysis of climate indices for the region using all CMIP5 models. Such analysis can further reduce the biases associated with the model selection and may lead to more accurate results.

\section{Conclusions}

In this study, the spatial and temporal trends in the frequency of extreme historical precipitation and temperature events, represented by PRCPTOT, R99p, CDD, CWD, TX10p, TN90p, TNn, and TXx, over southern Ontario were evaluated. These climate indices were computed using observed (ECCC and CanGrid) and climate model (CanRCM4 and three CMIP5 GCMs) datasets. The statistical significance of the trends has also been assessed. The main findings of this study can be summarized as follows.

- A decrease in the frequency of cold temperature extremes and increases in the frequency of warm extremes were found in the study area, over the historical 1950-2013 period. It was also observed that nighttime warming has been greater than daytime warming. The annual total precipitation and the frequency of extreme precipitation also increased over southern Ontario.

- Spatially, for the precipitation indices, no significant trends were found for PRCPTOT and R99p in the southwestern and central parts of Ontario. The highest PRCPTOT trends were found in the counties of 
Grey, Bruce, and Renfrew. The highest R99p trends were found in the eastern parts of the study area. For CWD, the highest trends were found close to Georgian Bay, which encompasses the counties of Simcoe, Grey, Dufferin, and Victoria, as well as the District of Muskoka. For the temperature indices, TN10p and TN90p show significant trends in more than $90 \%$ of the study area.

- Comparison between historical precipitation and temperature indices using ECCC and CanGrid datasets indicated good agreement between the index values computed using the two data sources. In term of linear trends, comparison showed that CanGrid data underestimated the linear trends showed in the ECCC station data

- The statistical bias-correction method generally improved the climate models' ability to accurately simulate observed trends in climate indices. Comparison between the climate model outputs and the observed historical time series indicated that the CCSM4 model developed by the National Center for Atmospheric Research provided the best performance in simulating the historically observed precipitation indices, and the CanESM2 model developed by the Canadian Center for Climate Modeling is a good model for simulating the historical observed temperature indices series, while CanRCM4 is a good model for simulating the historical observed trends in both the temperature and precipitation indices. We conclude that no single model can be regarded as "better" than any other for this region. Use of data from a particular model depends on the study objectives. Therefore, our recommendation for this region intersects with those of the climate modeling community, which uses ensemble or multimodel data for simulating future climate trends for regional and local studies.

Acknowledgments. Financial support for this study was provided by the Natural Sciences and Engineering Research Council (NSERC) of Canada through the NSERC Canadian FloodNet Project. Weather station, CanGrid, CanRCM, and CMIP5 data were obtained from the following websites, respectively: http://gdo-dcp.ucllnl.org/ downscaled_cmip_projections/dcpInterface.html, http:// www.cccma.ec.gc.ca/data/canrcm/CanRCM4/index cordex.shtml, http://climate.weather.gc.ca/climateData, and http://data.gc.ca/data/en/dataset/3d4b68a5-13bc-48bbad10-801128aa6604. These data sources and the researchers involved in compiling them are gratefully acknowledged. The authors express their appreciation to the reviewers and journal editors for their valuable comments and suggestions.

\section{REFERENCES}

Adamowski, J., K. Adamowski, and J. Bougadis, 2010: Influence of trend on short duration design storms. Water Resour. Manage., 24, 401-413, doi:10.1007/s11269-009-9452-z.

Alexander, L. V., and Coauthors, 2006: Global observed changes in daily climate extremes of temperature and precipitation. J. Geophys. Res., 111, D05109, doi:10.1029/2005JD006290.

Bonsal, B. R., X. Zhang, L. A. Vincent, and W. D. Hogg, 2001: Characteristics of daily and extreme temperatures over Canada. J. Climate, 14, 1959-1976, doi:10.1175/1520-0442(2001)014<1959: CODAET $>2.0 . \mathrm{CO} ; 2$.

Brekke, L., B. L. Thrasher, E. P. Maurer, and T. Pruitt, 2013: Downscaled CMIP3 and CMIP5 climate and hydrology projections: Release of downscaled CMIP5 climate projections, comparison with preceding information, and summary of user needs. Bureau of Reclamation, 47 pp., http://gdo-dcp.ucllnl. org/downscaled_cmip_projections/techmemo/downscaled_ climate.pdf.

Cannon, A. J., S. R. Sobie, and T. Q. Murdock, 2015: Bias correction of GCM precipitation by quantile mapping: How well do methods preserve changes in quantiles and extremes? J. Climate, 28, 6938-6959, doi:10.1175/JCLI-D-14-00754.1.

Caya, D., and R. Laprise, 1999: A semi-implicit semi-Lagrangian regional climate model: The Canadian RCM. Mon. Wea. Rev., 127, 341-362, doi:10.1175/1520-0493(1999)127<0341: ASISLR $>2.0 . \mathrm{CO} ; 2$.

Chaouche, K., L. Neppel, C. Dieulin, N. Pujol, B. Ladouche, E. Martin, D. Salas, and Y. Caballero, 2010: Analyses of precipitation, temperature and evapotranspiration in a French Mediterranean region in the context of climate change. C. $R$. Geosci., 342, 234-243, doi:10.1016/j.crte.2010.02.001.

Colombo, S. J., D. W. McKenney, K. M. Lawrence, and P. A. Gray, 2007: Climate change projections for Ontario: Practical information for policymakers and planners. Climate Change Research Rep. CCRR-05, Ontario Ministry of Natural Resources, Ontario, ON, Canada, 39 pp., http://www. climateontario.ca/MNR_Publications/276923.pdf.

DeBeer, C. M., H. S. Wheater, S. K. Carey, and K. P. Chun, 2016: Recent climatic, cryospheric, and hydrological changes over the interior of western Canada: A review and synthesis. Hydrol. Earth Syst. Sci., 20, 1573-1598, doi:10.5194/ hess-20-1573-2016.

Dibike, Y. B., and P. Coulibaly, 2007: Validation of hydrological models for climate scenario simulation: The case of Saguenay watershed in Quebec. Hydrol. Processes, 21, 3123-3135, doi:10.1002/hyp.6534.

Frich, P., L. V. Alexander, P. Della-Marta, B. Gleason, M. Haylock, A. M. G. K. Tank, and T. Peterson, 2002: Observed coherent changes in climatic extremes during the second half of the twentieth century. Climate Res., 19, 193-212, doi:10.3354/cr019193.

Gallo, K. P., D. R. Easterling, and T. C. Peterson, 1996: The influence of land use/land cover on climatological values of the diurnal temperature range. J. Climate, 9, 2941-2944, doi:10.1175/1520-0442(1996)009<2941:TIOLUC>2.0.CO;2.

Gent, P. R., and Coauthors, 2011: The Community Climate System Model version 4. J. Climate, 24, 4973-4991, doi:10.1175/ 2011JCLI4083.1.

Gillett, N. P., D. A. Stone, P. A. Stott, T. Nozawa, A. Yu. Karpechko, G. C. Heger, M. F. Wehner, and P. D. Jones, 2008: Attribution of polar warming to human influence. Nat. Geosci., 1, 750-754, doi:10.1038/ngeo338. 
Hofstra, N., M. Haylock, M. New, P. Jones, and C. Frei, 2008: Comparison of six methods for the interpolation of daily, European climate data. J. Geophys. Res., 113, D21110, doi:10.1029/2008JD010100.

Hopkinson, R. F., D. W. McKenney, E. J. Milewska, M. F. Hutchinson, P. Papadopol, and L. A. Vincent, 2011: Impact of aligning climatological day on gridding daily maximumminimum temperature and precipitation over Canada. J. Appl. Meteor. Climatol., 50, 1654-1665, doi:10.1175/2011JAMC2684.1.

Hutchinson, M. F., D. W. McKenney, K. Lawrence, J. H. Pedlar, R. F. Hopkinson, E. Milewska, and P. Papadopol, 2009: Development and testing of Canada-wide interpolated spatial models of daily minimum-maximum temperature and precipitation for 1961-2003. J. Appl. Meteor. Climatol., 48, 725-741, doi:10.1175/2008JAMC1979.1.

Ines, A. V. M., and J. W. Hansen, 2006: Bias correction of daily GCM rainfall for crop simulation studies. Agric. For. Meteor., 138, 44-53, doi:10.1016/j.agrformet.2006.03.009.

IPCC, 2013: Managing the Risks of Extreme Events and Disasters to Advance Climate Change Adaptation. Cambridge University Press, 582 pp.

Jones, P. D., S. C. B. Raper, R. S. Bradley, H. F. Diaz, P. M. Kellyo, and T. M. L. Wigley, 1986: Northern Hemisphere surface air temperature variations: 1851-1984. J. Climate Appl. Meteor., 25, 161-179, doi:10.1175/1520-0450(1986)025<0161: NHSATV $>2.0 . \mathrm{CO} ; 2$.

Kadioğlu, M., 1997: Trends in surface air temperature data over Turkey. Int. J. Climatol., 17, 511-520, doi:10.1002/ (SICI)1097-0088(199704)17:5<511::AID-JOC130>3.0.CO;2-0.

Karl, T. R., H. F. Diaz, and G. Kukla, 1988: Urbanization: Its detection and effect in the United States climate record. J. Climate, 1, 1099-1123, doi:10.1175/1520-0442(1988)001<1099: UIDAEI $>2.0 . \mathrm{CO} ; 2$.

Kendall, M. G., 1948: Rank Correlation Methods. C. Griffin, 160 pp.

Laprise, R., D. Caya, M. Giguere, G. Bergeron, H. Côté, J.-P. Blanchet, G. J. Boer, and N. A. McFarlane, 1998: Climate and climate change in western Canada as simulated by the Canadian Regional Climate Model. Atmos.-Ocean, 36, 119-167, doi:10.1080/07055900.1998.9649609.

Li, X., S. Zhong, X. Bian, W. E. Heilman, Y. Luo, and W. Dong, 2010: Hydroclimate and variability in the Great Lakes region as derived from the North American Regional Reanalysis. J. Geophys. Res., 115, D12104, doi:10.1029/2009JD012756.

Lu, E., and Coauthors, 2015a: Determining starting time and duration of extreme precipitation events based on intensity. Climate Res., 63, 31-41, doi:10.3354/cr01280.

— , and Coauthors, 2015b: The nonlinear relationship between summer precipitation in China and the sea surface temperature in preceding seasons: A statistical demonstration. J. Geophys. Res. Atmos., 120, 12027-12036, doi:10.1002/ 2015JD024030.

Mann, H. B., 1945: Nonparametric tests against trend. Econometrica, 13, 245-259, doi:10.2307/1907187.

Massey, F. J., 1951: The Kolmogorov-Smirnov test for goodness of fit. J. Amer. Stat. Assoc., 46, 68-78, doi:10.1080/ 01621459.1951.10500769.

Maurer, E. P., L. Brekke, T. Pruitt, and P. B. Duffy, 2007: Fineresolution climate projections enhance regional climate change impact studies. Eos, Trans. Amer. Geophys. Union, 88, 504-504, doi:10.1029/2007EO470006.

McKenney, D. W., and Coauthors, 2011: Customized spatial climate models for North America. Bull. Amer. Meteor. Soc., 92, 1611-1622, doi:10.1175/2011BAMS3132.1.
Minville, M., F. Brissette, and R. Leconte, 2008: Uncertainty of the impact of climate change on the hydrology of a Nordic watershed. J. Hydrol., 358, 70-83, doi:10.1016/ j.jhydrol.2008.05.033.

Moberg, A., and P. D. Jones, 2005: Trends in indices for extremes in daily temperature and precipitation in central and western Europe, 1901-99. Int. J. Climatol., 25, 1149-1171, doi:10.1002/ joc.1163.

Mohsin, T., and W. A. Gough, 2010: Trend analysis of longterm temperature time series in the Greater Toronto Area (GTA). Theor. Appl. Climatol., 101, 311-327, doi:10.1007/ s00704-009-0214-x.

Paixao, E., H. Auld, M. M. Q. Mirza, J. Klaassen, and M. W. Shephard, 2011: Regionalization of heavy rainfall to improve climatic design values for infrastructure: Case study in southern Ontario, Canada. Hydrol. Sci. J., 56, 1067-1089, doi:10.1080/02626667.2011.608069.

Peterson, T. C., and M. J. Manton, 2008: Monitoring changes in climate extremes: A tale of international collaboration. Bull. Amer. Meteor. Soc., 89, 1266-1271, doi:10.1175/2008BAMS2501.1.

Rapaić, M., R. Brown, M. Markovic, and D. Chaumont, 2015: An evaluation of temperature and precipitation surfacebased and reanalysis datasets for the Canadian Arctic, 1950-2010. Atmos.-Ocean, 53, 283-303, doi:10.1080/ 07055900.2015 .1045825 .

Razavi, T., H. Switzman, A. Arain, and P. Coulibaly, 2016: Regional climate change trends and uncertainty analysis using extreme indices: A case study of Hamilton, Canada. Climate Risk Manage., 13, 43-63, https://doi.org/10.1016/j.crm.2016.06.002.

Sharma, M., P. Coulibaly, and Y. Dibike, 2011: Assessing the need for downscaling RCM data for hydrologic impact study. J. Hydrol. Eng., 16, 534-539, doi:10.1061/ (ASCE)HE.1943-5584.0000349.

Taylor, K. E., 2001: Summarizing multiple aspects of model performance in a single diagram. J. Geophys. Res., 106, 7183-7192, doi:10.1029/2000JD900719.

- R. J. Stouffer, and G. A. Meehl, 2012: An overview of CMIP5 and the experiment design. Bull. Amer. Meteor. Soc., 93, 485-498, doi:10.1175/BAMS-D-11-00094.1.

Tebaldi, C., and R. Knutti, 2007: The use of the multi-model ensemble in probabilistic climate projections. Philos. Trans. Roy. Soc., 365A, 2053-2075, doi:10.1098/rsta.2007.2076.

Thorne, R., and M. A. Arain, 2015: Influence of low frequency variability on climate and carbon fluxes in a temperate pine forest in eastern Canada. Forests, 6, 2762-2784, doi:10.3390/ f6082762.

Vicente-Serrano, S., M. A. Saz-Sánchez, and J. M. Cuadrat, 2003: Comparative analysis of interpolation methods in the middle Ebro Valley (Spain): Application to annual precipitation and temperature. Climate Res., 24, 161-180, doi:10.3354/cr024161.

Vincent, L. A., and É. Mekis, 2006: Changes in daily and extreme temperature and precipitation indices for Canada over the twentieth century. Atmos.-Ocean, 44, 177-193, doi:10.3137/ao.440205.

_ X. X. Wang, E. J. Milewska, H. Wan, F. Yang, and V. Swail, 2012: A second generation of homogenized Canadian monthly surface air temperature for climate trend analysis. J. Geophys. Res., 117, D18110, doi:10.1029/2012JD017859.

— X. Xhang, R. D. Brown, Y. Feng, E. Mekis, E. J. Milewska, H. Wan, and X.L. Wang, 2015: Observed trends in Canada's climate and influence of low-frequency variability modes. J. Climate, 28, 4545-4560, doi:10.1175/JCLI-D-14-00697.1.

Wan, H., X. Zhang, F. Zwiers, and S.-K. Min, 2015: Attributing northern high-latitude precipitation change over the period 
1966-2005 to human influence. Climate Dyn., 45, 1713-1726, doi:10.1007/s00382-014-2423-y.

Warren, F. J., and D. S. Lemmen, 2014: Canada in a Changing Climate: Sector Perspectives on Impacts and Adaptation. Natural Resources Canada, 286 pp.

Whan, K., and F. Zwiers, 2016: Evaluation of extreme rainfall and temperature over North America in CanRCM4 and CRCM5. Climate Dyn., 46, 3821-3843, doi:10.1007/s00382-015-2807-7.

Zhang, X., L. A. Vincent, W. D. Hogg, and A. Niitsoo, 2000: Temperature and precipitation trends in Canada during the 20th century. Atmos.-Ocean, 38, 395-429, doi:10.1080/ 07055900.2000 .9649654$.

F. W. Zwiers, and P. A. Stott, 2006: Multimodel multisignal climate change detection at regional scale. J. Climate, 19, 4294-4307, doi:10.1175/JCLI3851.1.

, R. Brown, L. Vincent, W. Skinner, Y. Feng, and E. Mekis, 2011: Canadian climate trends, 1950-2007. Tech. Thematic Report Series, No. 5, Canadian Councils of Resource Ministers, 21 pp., http://publications.gc.ca/collections/collection_ 2011/ec/En14-43-5-2011-eng.pdf. 